\title{
An empirical analysis of retirement behaviour in Spain: partial versus full retirement
}

\author{
Isabel Cairó-Blanco
}

Received: 22 July 2007 / Accepted: 28 October 2009/Published online: 14 January 2010

(C) Spanish Economic Association and Fundación SEPI 2010

\begin{abstract}
In several developed countries, the ageing process of the population may pose fiscal risks to the PAYG systems of public pensions. This paper studies the determinants of two forms of accessing retirement in Spain, either partial or full retirement. Our goal is to identify if social security legislation influences the choice between these two alternative paths. Using a newly released data set we estimate a multinomial logit duration model including different measures capturing the economic incentives embedded in the social security system. Our results show that social security incentives determine individual retirement decisions. Besides, partial retirement legislation modifies the selection of retirement routes and affects the age of retirement moving it to an earlier date.
\end{abstract}

Keywords Retirement $\cdot$ Public pensions · Duration analysis

JEL Classification $\mathrm{C} 41 \cdot \mathrm{H} 55 \cdot \mathrm{J} 14 \cdot \mathrm{J} 26$

\section{Introduction}

Several developed countries may face fiscal risks stemming from the lack of financial sustainability of their pay-as-you-go (PAYG) public pension systems. Two major trends are behind this, the ageing process of the population-due to the

This paper is a revised version of my Master's Thesis presented in partial fulfillment of the 2005-2007 Master in Economics and Finance at CEMFI.

I. Cairó-Blanco $(\bowtie)$

Department of Economics, Universitat Pompeu Fabra, Ramon Trias Fargas 25-27,

08005 Barcelona, Spain

e-mail: isabel.cairo@upf.edu 
increase in life expectancy at birth and the decline in fertility rates-and the shortening of professional lifes, also driven by the increase in early retirement. All these elements have implications for the evolution of the labour force structure and on the dependency ratio which is a key determinant to the viability of PAYG systems - such as the spanish one. For this reason, it is important to understand which factors influence retirement decisions.

The effect that the social security system has upon the observed behaviour is essential. A wide range of worldwide studies have tried to assess the quantitative importance of these effects. Blondal and Scarpetta (1998) and Gruber and Wise (1999, 2004) have suggested that individual retirement decisions are strongly affected by the design of the social security system. Börsch-Supan (2000) argues that workers have responded consistently and strongly to the economic incentives to retire earlier in Germany. Gruber and Wise (1999), for the case of Spain, find evidence that the social security legislation generates strong incentives to retire early and the main inducement comes from the generous mechanism determining the minimum pension, specially for low earners. With the aim of changing the retirement incentives of older workers, the spanish government launched a reform of the pension system in 1997 and an amendment to it in 2002. Partial retirement, as a form of accessing pension benefits, was regulated in Spain in 2002. ${ }^{1}$ The objective of this regulation was making the access to retirement a more flexible process, avoiding a sharp break between working and retirement. Since then, the use of partial retirement as a form of entering retirement has dramatically increased. Therefore, it is relevant to know if the legislation of partial retirement modifies retirement patterns towards postponing the age of definitely exiting the labour force participation-and thus incrementing activity rates of older people-or if it is actually creating incentives to advance retirement. For this, understanding the determinants of partial retirement is an important step. It is hoped that the nonapplicability of reduction coefficients in case of partial retirement before the age of 65 is a potential source of making this exit route a dominant strategy against early retirement, at least at an early age.

Different studies have tried to understand the determinants of many possible exit routes from employment available in Spain. Older workers use either early retirement, ordinary retirement, temporary illness or disability or temporary leave from the labour force as pathways to a situation of non-participation. Blanco (2000) studies, using the Spanish Household Panel Survey, two alternative routes for entering retirement in Spain: pure early retirement or disability. Boldrin et al. (1999, 2004) assess the role that social security incentives are playing on early retirement decision, using a random draw from the administrative records from the Spanish Social Security Administration. Argimón et al. (2009) carried out a similar analysis estimating a duration model and computing the effects of the reform that took place in 2002, using the Continuous Sample of Working Histories (Muestra Continua de Vidas Laborales, MCVL). Jiménez-Martín and

\footnotetext{
1 The regulation comes through the Law 35/2002. However, the figure of partial retirement is present in the Spanish Social Security System since 1994, when the General Social Security Act (Ley General de la Seguridad Social) was promulgated.
} 
Vall-Castelló (2009) analyze transitions from employment to unemployment, disability pensions and inactivity of spanish workers aged 45-59 incorporating business cycle indicators. However, the possible differential pattern between partial and full retirement has not yet been analysed in Spain mainly because of two reasons: the practically nonexistent use of partial retirement before 2002 and the absence of detailed microeconometric data. The MCVL allows to precisely identify partial retirement.

Therefore, the aim of this study is to identify the determinants of two forms of accessing pension benefits by men aged between 60 and 65 in Spain: either partial or full retirement. Special interest is devoted both to assess the explanatory power of different measures capturing the economic incentives embedded in the social security system into the alternative retirement routes and to identify if these incentives can influence the choice between them. It is of main interest to know what drives retirement decisions in order to design suitable policies. The idea is that if a policy whose aim is to retain old workers at work is not well designed, it will create greater incentives to leave earlier the contributory life.

The rest of this paper is organized as follows. In Sect. 2 a summary of the spanish social security legislation is provided. Section 3 describes the econometric specification. Section 4 offers a description of the data set and presents the social security incentives. Section 5 shows the estimation results. Finally, Sect. 6 concludes.

\section{Institutional features: retirement rules}

This section briefly describes the rules governing retirement systems in Spain since 1997 and the 2002 amendment. Given that the objective is to analyze the retirement decision in ages ranging from 60 to 65 , we focus only on the corresponding legislation. For a complete description of the spanish social security system see Boldrin et al. (2004).

Spain has a mandatory PAYG system where pension benefits are mainly provided under two schemes: General Social Security System (Régimen General de la Seguridad Social, RGSS) and Special Social Security System (Regímenes Especiales de la Seguridad Social, RESS). The General Regime is a pure PAYG system and it is the one with the greatest percentage of covered workers. Specifically, $77 \%$ of workers were covered by the RGSS in 2005, the year of extraction of the data used in the analysis. This study focuses only on that system. Qualifying to receive an old-age benefit is conditional on several requirements. The main ones are the attainment of a specified age and a minimum period of contribution and total or substantial withdrawal from the labour force, if the participation requires the worker to contribute to the system. Regarding to the minimum period of contributions, entitlement to an old age pension requires at least 15 years of contributions, two of them within the 15 years immediately previous to the time of becoming eligible to the benefit. The following two alternative routes for entering retirement are considered: 
- Full retirement. An individual can fully retire through three different paths: ordinary retirement, early retirement and special retirement at the age of 64 . The ordinary retirement age is 65 . For those who started contributing to the system after 1967 and since the 2002 amendment, early retirement at age 61 is permitted with strict requirements. Namely, they have to (a) certify a minimum effective contribution period of 30 years, (b) be registered as a job seeker, in the public employment service offices, during a period of 6 months immediately prior to the date of the retirement application and (c) the job termination should not been caused by worker's free will. Early retirement at age 60 is permitted (if the minimum period of contributions is satisfied), according to the rules of a transient law, for those who contributed to labour mutual funds that preceded the establishment of the social security system. The amount of all early retirement pensions are subject to reduction coefficients. Finally, retirement at 64 years, certifying the minimum period of contributions, is possible if the firm hires another worker for a minimum period of 1 year to replace the retiree. In this latter case the retiree is eligible to full benefits and no reduction coefficients are applied.

- Partial retirement. An employee who has reached the age of 60 and meets the entitlement conditions required to earn the right to the contributory social security retirement pension, may apply for partial retirement. The worker must arrange, by agreement with the firm, a part-time contract that reduces the working day and salary by a minimum of $25 \%$ and a maximum of $85 \%$ each. If the worker applies for partial retirement at an age less than 65 the firm will arrange a simultaneous relief contract, in order to fill the working day left vacant by the partially retired worker. In cases in which the worker applies for partial retirement at the age of 65 or older, it is not necessary to arrange a relief contract provided that the other requirements are met. Relief and part-time contracts are strictly regulated by law.

When eligibility conditions are satisfied, the initial pension a retired individual is going to receive is determined by applying a percentage called the replacement rate $\left(\alpha_{t}\right)$ to the regulating base $\left(\mathrm{RB}_{t}\right)$ as shown in expression (1).

$$
P_{t}=\alpha_{t} \mathrm{RB}_{t}
$$

The regulating base is, since 2002 and as expressed in (2), a weighted average of the contribution bases $^{2}\left(B_{t}\right)$ in the 180 months prior to retirement, that is 15 years of contributory life. ${ }^{3}$ Before 1997 the number of years of reference was only eight. Starting from 1997, this number increased by 1 year until 2001, reaching 15 in 2002.

\footnotetext{
${ }^{2}$ Bases of the contribution are a doubly censored version of monthly earnings. Lower and upper ceilings are legislated annually and depend on the contributive group.

3 The legislation gives a rule of gap integration in case there are months when the worker had no obligation to make contributions. These contribution gaps will be integrated with the minimum contribution bases in the RGSS for workers over 18 years of age. Note also that, as pensions are paid fourteen times during a year, expression (2) is divided by 210.
} 


$$
\mathrm{RB}_{t}=\frac{1}{210}\left(\sum_{i=1}^{24} B_{t-i}+\sum_{i=25}^{180} B_{t-i} \frac{I_{t-25}}{I_{t-i}}\right)
$$

where $I_{t}$ corresponds to the consumer price index (CPI) at period $t$.

The replacement rate depends on the number of years of contribution to the system $(n)$ and on the age of the retiree $(a)$. In case of ordinary retirement

$$
\alpha_{t}=\left\{\begin{array}{cl}
0 & \text { if } n<15 \\
0.5+0.03(n-15) & \text { if } 15 \leq n \leq 25 \\
0.8+0.02(n-25) & \text { if } 25<n<35 \\
1 & \text { if } n \geq 35
\end{array}\right.
$$

In case of early retirement, there is a reduction coefficient $(k)$ for each age previous to the ordinary age of retirement. The scheme of penalization was modified in the 2002 amendment making it more dependent on the number of years of contributory life.

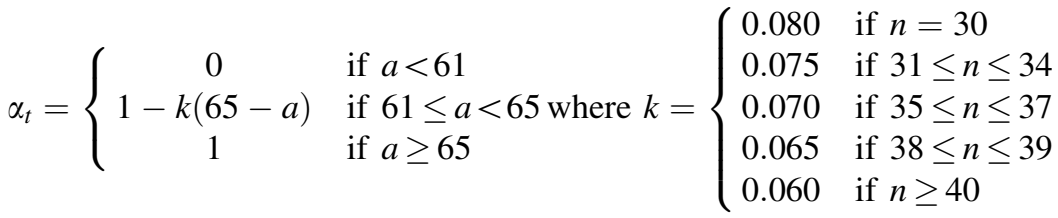

Before the 2002 amendment the replacement rate in case of early retirement was

$$
\alpha_{t}=\left\{\begin{array}{cl}
0 & \text { if } a<60 \\
0.60+0.08(a-60) & \text { if } 60 \leq a<65 \text { and } n<40 \\
0.65+0.07(a-60) & \text { if } 60 \leq a<65 \text { and } n \geq 40 \\
1 & \text { if } a \geq 65
\end{array}\right.
$$

The 2002 legislation introduced a premium for late retirement, so that

$$
\alpha_{t}=1+0.02(a-65) \text { if } a>65 \text { and } n \geq 35
$$

In case of partial retirement, reduction coefficients are not applied when the worker retires before reaching the age of 65 . Moreover, the resulting pension amount is reduced by the working day reduction percentage.

Contributory social security pensions are subject to minimum and maximum ceilings legislated annually. Other things being equal, minimum pensions are higher for those who are older than 65 and/or have a dependent spouse. Furthermore, all pensions, including minimum pensions, are revalued at the beginning of each year based on the CPI forecast for that year. If the cumulative CPI is greater than the forecast CPI used to calculate the revaluation, an appropriate update is made.

\section{Econometric model}

The approach used to model retirement decisions is not a structural representation of the choice between partial and full retirement. The retirement decision 
is in fact modelled using a reduced-form approach, as in Gruber and Wise (2004), and no labour demand considerations are taken into account. An alternative approach is the option value developed by Stock and Wise (1990), in which a representative agent considers the flow of expected future utilities to continue working against retirement. Particularly, the retirement decision of the individual is affected not only by retirement benefits, but also by the future evolution of work and wealth. Another alternative approach is to consider a full life-cycle model, which an example for the spanish case is developed by Jiménez-Martín and Sánchez-Martín (2007). For simplicity, this paper follows a hazard rate approach to capture the effects of personal characteristics, contributory life characteristics and social security incentives on the path to enter retirement. Following Bover and Gómez (2004), we consider a model in which there is more than one possible exit from full time labour force participation or equivalently in our context, more than one possible entry to retirement: either partially or fully. We assume that individuals will choose to not retire if the utility of remaining in their current situation is greater than the utility of retiring, either fully or partially. If we have a discrete duration variable $T$ and two alternatives represented by the indicators $D_{F}$ and $D_{P}$, where $F$ and $P$ identify full and partial retirement respectively, we can define the following intensities of transition to each of the states:

$$
\begin{aligned}
& \phi_{F}(t)=\operatorname{Pr}\left(T=t, D_{F}=1 \mid T \geq t\right) \\
& \phi_{P}(t)=\operatorname{Pr}\left(T=t, D_{P}=1 \mid T \geq t\right)
\end{aligned}
$$

In our context, $T$ represents the duration of a situation of non-retirement and $\phi_{F}(t)$ is the probability of exiting to full retirement at $T=t$ among those who remain nonretired for at least $T \geq t$ periods. Equivalently, $\phi_{P}(t)$ is the probability of exiting to partial retirement at $T=t$ among those who remain non-retired for at least $T \geq t$ periods. So, the hazard rate from a situation of non-retirement is given by:

$$
\phi(t)=\phi_{F}(t)+\phi_{P}(t)
$$

As pointed out by different authors (Narendranathan and Stewart 1993a, b; Sueyoshi 1995; Jenkins 1995) a discrete duration model can be regarded as a sequence of discrete choice models-with cross-equation restrictions-defined on the surviving population at each duration. This provides a useful perspective for computational reasons that can be easily understood firstly by introducing a sequence of exit indicators at $t$ to a given alternative:

$$
Y_{F t}=\mathbf{1}\left(T=t, D_{F}=1\right), Y_{P t}=\mathbf{1}\left(T=t, D_{P}=1\right) \text { for } t=1,2,3, \ldots
$$

According to this notation,

$$
\begin{aligned}
& \phi_{F}(t)=\operatorname{Pr}\left(Y_{F t}=1 \mid T \geq t\right) \\
& \phi_{P}(t)=\operatorname{Pr}\left(Y_{P t}=1 \mid T \geq t\right)
\end{aligned}
$$

Alternatively, we can define exit rates to each of the states conditional upon not exiting to the alternative state: 


$$
\begin{aligned}
& h_{F}(t)=\operatorname{Pr}\left(Y_{F t}=1 \mid T \geq t, Y_{P t}=0\right) \\
& h_{P}(t)=\operatorname{Pr}\left(Y_{F t}=1 \mid T \geq t, Y_{F t}=0\right)
\end{aligned}
$$

So, $h_{F}(t)$ is the probability of exiting to full retirement at $T=t$ among those who remain non-retired for at least $T \geq t$ periods and do not exit to partial retirement at $T=t$. Equivalently, $h_{P}(t)$ is the probability of exiting to partial retirement at $T=t$ among those who remain non-retired for at least $T \geq t$ periods and do not exit to full retirement at $T=t$.

The relationship with the previous transition intensities is given by:

$$
h_{F}(t)=\frac{\operatorname{Pr}\left(Y_{F t}=1 \mid T \geq t\right)}{\operatorname{Pr}\left(Y_{P t}=0 \mid T \geq t\right)}=\frac{\phi_{F}(t)}{1-\phi_{P}(t)}
$$

and similarly

$$
h_{P}(t)=\frac{\phi_{P}(t)}{1-\phi_{F}(t)}
$$

Therefore, in the context of variables and multiple exit alternatives, we can choose between modelling the intensities $\phi_{j}(t)$ or the conditional hazard rates $h_{j}(t)$. The models for the conditional probabilities are usually called competing risk models. This name derives from the fact that if we consider the existence of two latent duration variables $T_{1}^{*}$ and $T_{2}^{*}$, such that the observed duration is $T=\min \left\{T_{1}^{*}, T_{2}^{*}\right\}$ and $T_{1}^{*}, T_{2}^{*}$ are independent, then the conditional exit rates can be interpreted as exit rates for the latent durations:

$$
\begin{aligned}
& h_{1}(t)=\operatorname{Pr}\left(T_{1}^{*}=t \mid T_{1}^{*} \geq t\right) \\
& h_{2}(t)=\operatorname{Pr}\left(T_{2}^{*}=t \mid T_{2}^{*} \geq t\right)
\end{aligned}
$$

That is, to analyze exits to alternative 1 we take the exits to alternative 2 as censored observations, and vice versa. Note that irrespective of whether $T_{1}^{*}, T_{1}^{*}$ correspond to well defined concepts, $h_{1}(t), h_{2}(t)$ generally represent useful descriptive characteristics for the durations and exits observed.

We use the multinomial logit model, a specification commonly used in multiple choice problems. Consequently, the dependence of $\phi_{F}(t)$ and $\phi_{P}(t)$ on the explanatory variables $x$ is specified by:

$$
\begin{aligned}
& \phi_{F}(t)=\frac{e^{x^{\prime} \beta_{F}}}{1+e^{x^{\prime} \beta_{F}}+e^{x^{\prime} \beta_{P}}} \\
& \phi_{P}(t)=\frac{e^{x^{\prime} \beta_{P}}}{1+e^{x^{\prime} \beta_{F}}+e^{x^{\prime} \beta_{P}}}
\end{aligned}
$$

Note that, in accordance with the relationships given above, this specification for $\phi_{F}(t)$ and $\phi_{P}(t)$ implies that

$$
\begin{aligned}
& h_{F}(t)=\frac{e^{x^{\prime} \beta_{F}}}{1+e^{x^{\prime} \beta_{F}}} \\
& h_{P}(t)=\frac{e^{x^{\prime} \beta_{P}}}{1+e^{x^{\prime} \beta_{P}}}
\end{aligned}
$$


So, if the transition intensities are modelled as multinomial logit, the conditional exit rates are binary logit with the same parameters. As a result, the use of the logistic specification leads to the same model in both cases.

The method used to obtain the estimation of the parameters of the logistic specification $\left(\beta_{F}, \beta_{P}\right)$ is conditional maximum likelihood. The conditional loglikelihood function to exit $\mathrm{F}$ is given by the sum of the contributions of the $N$ individuals

$$
\begin{aligned}
L_{F}\left(\beta_{F}\right)= & \sum_{i=1}^{N}\left[c_{i}\left(D_{F i} \log h_{F i}\left(d_{i}\right)+D_{F i} \sum_{t=1}^{d_{i}-1} \log \left(1-h_{F i}(t)\right)\right)\right. \\
& \left.+\left[D_{P i}+\left(1-c_{i}\right)\right] \sum_{t=1}^{d_{i}} \log \left(1-h_{F i}(t)\right)\right]
\end{aligned}
$$

where $d_{i}$ is the observed duration and $c_{i}$ is a censoring indicator which takes the value 1 if the entry to retirement is observed, and 0 if it is not.

That is, the conditional maximum likelihood estimators defined as the maximisers of $L_{F}\left(\beta_{F}\right)$ and $L_{P}\left(\beta_{P}\right)$, respectively, can be obtained as separate maximum-likelihood estimates of both binary logit models. It is important to note that in $L_{F}\left(\beta_{F}\right)$ the exits to partial retirement are treated as censored observations. Having obtained estimates of the parameters $\beta_{F}, \beta_{P}$ we can obtain different measures of the effect of the explanatory variables on the probabilities of choosing a specific retirement route depending on whether $\phi_{j}(t)$ or $h_{j}(t)$ are the focus of the analysis.

\section{Data and empirical analysis}

\subsection{Data set}

The empirical analysis of the retirement decision is based on the Continuous Sample of Working Histories (Muestra Continua de Vidas Laborales, MCVL) wave 2005. It is an administrative data set based on a random draw from the Spanish Social Security records. It contains a sample of $4 \%$ of the population of reference which is formed by all the individuals that at any time during 2005 were either contributing towards the social security system or perceiving a contributory pension. Contributory pensions include: old-age pensions, disability pensions, widowhood pensions, orphanage pensions and family pensions. The data set provides information about the entire labour history of workers, for instance the exact duration of each employment and unemployment spells, the firm's sector of activity, the type of contract held, the wages measured as contribution bases, etc. The MCVL is particularly attractive for the study of retirement behaviour because it contains the main parameters to calculate pension rights. For pensioners, the data set offers detailed information about the type of pension received. Personal characteristics as age, gender, nationality, level of education, etc. are also collected. For a full description of the data set see MTAS (2006). 
Table 1 Distribution of individuals. If censored, broken down by age in 2005 and if retired, broken down by type and age of initial retirement

\begin{tabular}{|c|c|c|c|c|c|c|}
\hline \multirow{2}{*}{ Age } & \multicolumn{2}{|c|}{ Censored } & \multicolumn{2}{|c|}{ Fully retired } & \multicolumn{2}{|c|}{ Partially retired } \\
\hline & Number & $\%$ & Number & $\%$ & Number & $\%$ \\
\hline 60 & 6,607 & 23.64 & 8,309 & 39.05 & 1,333 & 63.48 \\
\hline 61 & 5,660 & 20.25 & 1,547 & 7.27 & 340 & 16.19 \\
\hline 62 & 5,334 & 19.08 & 1,525 & 7.17 & 258 & 12.29 \\
\hline 63 & 4,134 & 14.79 & 1,285 & 6.04 & 106 & 5.05 \\
\hline 64 & 3,277 & 11.72 & 1,832 & 8.61 & 22 & 1.05 \\
\hline 65 & 1,904 & 6.81 & 6,781 & 31.87 & 41 & 1.95 \\
\hline Greater than 65 & 1,034 & 3.70 & & & & \\
\hline Total & 27,950 & 100 & 21,279 & 100 & 2,100 & 100 \\
\hline
\end{tabular}

Individuals are censored either because we observe them up to a certain age, because we do not observe them retire or because they do it after the age of 65

As the objective of the paper is to analyze transitions from a situation of nonretirement into retirement, either partial or full, in ages ranging from 60 to 65 , neither transitions from partial retirement to full retirement nor transitions from full retirement to flexible retirement ${ }^{4}$ are studied. Thus, we focus on the first transition into retirement and if the partial retirement route is chosen, we assume for simplicity that the final age to enter full retirement is exogenously fixed. Therefore, an individual is considered fully retired if she starts receiving a contributory pension stemming from either early retirement, special retirement at the age of 64 or ordinary retirement, and is considered partially retired in case of starting perceiving a contributory pension stemming from partial retirement. The use of administrative data has the main advantage of avoiding relying on self-reported information, which might suffer from measurement error, or on arbitrary definitions of partial retirement based upon labour market activity, as for example the number of hours worked per week used in Sueyoshi (1989).

The study is restricted to individuals between 60 and 68 years old in 2005 (i.e. born between 1937 and 1945), with working records in the RGSS and not retired before they are 60 . The reasons are that we are only interested in retirement decisions in ages between 60 and 65 and that data on contributive pensions is only well recorded after 1996. So, we focus on individuals aged 60 or more between 1997 and 2005, the year of extraction of the data set used in the analysis. Moreover, as marital status is not known we do not examine the retirement decision in a household framework and we decided to restrict the analysis to men. Our sample contains 51,329 individuals, 23,379 of which enter retirement between 60 and 65 years old. The rest of individuals are censored, either because we observe them up to a certain age, because we do not observe them retire or because they do it after

\footnotetext{
${ }^{4}$ The situation of flexible retirement is the possibility of making the full retirement pension compatible, once in effect, with a part-time contract. This figure was introduced in the 2002 amendment.
} 


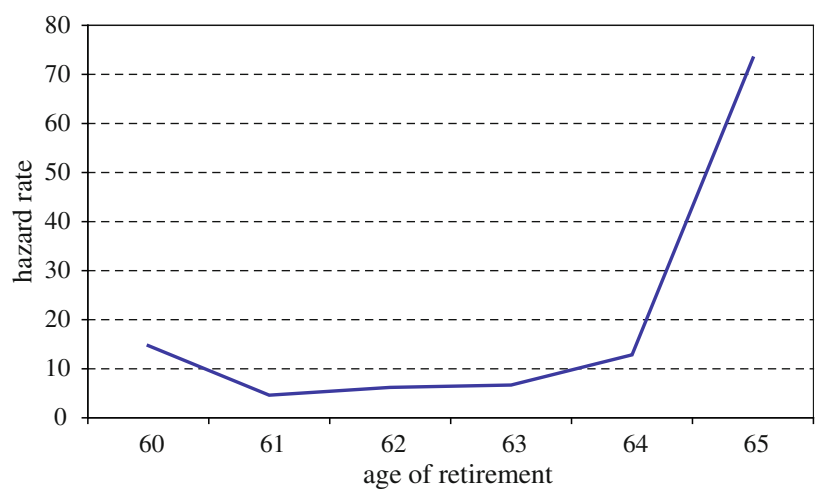

Fig. 1 Empirical hazard rate to full retirement

the age of 65. Table 1 shows the distribution of individuals: if censored, broken down by age in 2005 and if retired, broken down by type and age of initial retirement. As it can be seen, the use of partial retirement as a form of accessing pension benefits is not as extended as early retirement.

As shown in Table 1, the majority of individuals who partially retire do it at 60 , the first year in which older workers have the option to partially retire, and the majority of individuals who fully retired do it before the ordinary age of retirement. Major differences between the two risks become apparent when observing the empirical hazard rates presented in Figs. 1 and 2. It is necessary to point out the important difference in the magnitude as well as in the shape of the hazard rates to the two types of exits. In the case of full retirement we observe two spikes, one at 60 and a more pronounced one at the ordinary age of retirement, whereas in the case of partial retirement we only observe one spike at 60 . This evidence is consistent with the hypothesis that the underlying determinants of the two forms of retirement paths are potentially different.

The variables that are taken into account include personal characteristics, contributory life characteristics and social security incentives which are introduced in the next section. See Appendix for a description of the rest of the variables.

We cannot take fully into account some determinants of the retirement decision because the information was not collected in the data set. First of all, there is no information about health status. Poor health is expected to change preferences and should have, a priori, a positive impact upon retirement probabilities. As the data set includes information about disability pensions, we use the receipt of this pensions as a control for poor health. The idea is to take into account that health could be one of the primary determinants of retirement age. Secondly, the data set is relatively poor in information about the role that firms play in retirement decisions. It is reasonable to think that retirement choices depend on firm's action. This is particularly true in the case of partial retirement before the age of 65 , given that the worker has to reach an agreement with the firm in order to arrange a relief contract. The absence of a variable controlling for this fact could lessen the explanatory power of the social 


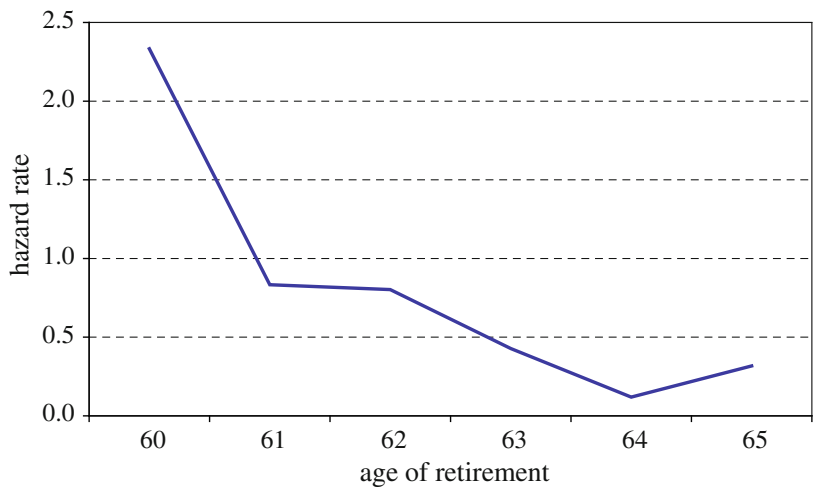

Fig. 2 Empirical hazard rate to partial retirement

security incentives on retirement decisions. Finally, there is no information of other sources of wealth, neither private pension plans nor non-labour income. However, the level of education and the sector of activity could capture, even through an indirect way, part of their effect.

\subsection{Evaluation of social security incentives}

To properly evaluate the economic incentives embedded in the social security system the approach adopted by Boldrin et al. (2004) is followed with some new definitions considering partial retirement. We express the incentives in monetary terms rather than in utility terms. This approach has the advantage that the results are not affected by assumptions concerning the difference in utility between partial and full retirement pensions. For an individual of age $a$, we firstly define social security wealth (SSW) in case of full retirement at age $h \geq a$ as the expected present value of future pension benefits

$$
\mathrm{SSW}_{h}^{F}=\sum_{s=h+1}^{S} \rho_{s} P_{s}^{F}(h)
$$

where $S$ is the certain age of death, $\rho_{s}=\beta^{s-a} \pi_{s}$, with $\beta$ denoting the pure time discount factor and $\pi_{s}$ the conditional probability for an individual aged $a$ to be alive at age $s$, and $P_{s}^{F}(h)$ the annual pension expected at age $s \geq h+1$ in case of full retirement at age $h$.

We can also define SSW for a worker who decides to partially retire at age $h \geq a$ and remain in that situation until age $b>h \geq a$, when the individual finally fully retires, as the expected value of future pension benefits

$$
\mathrm{SSW}_{h}^{P}=\sum_{s=h+1}^{b} \rho_{s} P_{s}^{P}(h)+\sum_{s=b+1}^{S} \rho_{s} P_{s}^{F P}(b, h)
$$


where $P_{s}^{P}(h)$ is the annual pension expected at age $s \geq h+1$ in case of partial retirement at age $h$ and $P_{s}^{F P}(b, h)$ is the annual pension expected at age $s \geq b+1>h \geq a$ in case of partial retirement at age $h$ and then enter full retirement at age $b$. Note that the worker spends $(b-h)$ periods in a situation of partial retirement before entering full retirement at age $b$. It is worth noting that the individual is going to make one joint decision: the age of retirement $h$ and the retirement path, whether fully or partially.

Given $\mathrm{SSW}^{j}$, where the superscript $j$ identifies the retirement route, full $(F)$ or partial $(P)$, let us define three incentive variables for an individual of age $a$.

1. The social security accrual (SSA) is the difference in SSW from postponing retirement from age $a$ to age $a+1$

(a) in case of full retirement:

$$
\begin{aligned}
\operatorname{SSA}_{a}^{F} & =\operatorname{SSW}_{a+1}^{F}-\operatorname{SSW}_{a}^{F} \\
& =\sum_{s=a+2}^{S} \rho_{s}\left[P_{s}^{F}(a+1)-P_{s}^{F}(a)\right]-\rho_{a+1} P_{a+1}^{F}(a)
\end{aligned}
$$

The $\operatorname{SSA}^{F}$ is positive if the expected present value of the increment in the flow of full pension benefits, that is if

$$
\sum_{s=a+2}^{S} \rho_{s}\left[P_{s}^{F}(a+1)-P_{s}^{F}(a)\right]
$$

is greater than the expected present value of the full pension benefit foregone by postponing, one single period, full retirement, that is $\rho_{a+1} P_{a+1}^{F}(a)$. If the increments $P_{s}^{F}(a+1)-P_{s}^{F}(a)$ are small then the $\operatorname{SSA}^{F}$ is negative. The rescaled negative accrual $\tau_{a}^{F}=-\operatorname{SSA}_{a}^{F} / W_{a+1}$, where $W_{a+1}$ equals expected earnings at age $a+1$ based on the information available up to age $a$, is called the implicit tax/subsidy on postponing full retirement from age $a$ to age $a+1$. The intuition behind this measure is that a negative accrual can be interpreted as a tax on further labour force participation. We therefore compute as an implicit tax rate the ratio of the (negative) accrual to the wage that workers would earn if they postponed full retirement at age $a$. As pointed out by Dekkers (2007), the advantage of using the implicit tax rate over the SSA is that it has no scale, and therefore is suitable for comparisons between groups of individuals.

(b) in case of partial retirement, and in an analogous way,

$$
\mathrm{SSA}_{a}^{P}=\mathrm{SSW}_{a+1}^{P}-\mathrm{SSW}_{a}^{P}
$$

where 


$$
\begin{aligned}
\mathrm{SSW}_{a+1}^{P} & =\sum_{s=a+2}^{b} \rho_{s} P_{s}^{P}(a+1)+\sum_{s=b+1}^{S} \rho_{s} P_{s}^{F P}(b, a+1) \\
\mathrm{SSW}_{a}^{P} & =\sum_{s=a+1}^{b} \rho_{s} P_{s}^{P}(a)+\sum_{s=b+1}^{S} \rho_{s} P_{s}^{F P}(b, a) \\
& =\rho_{a+1} P_{a+1}^{P}(a)+\sum_{s=a+2}^{b} \rho_{s} P_{s}^{P}(a)+\sum_{s=b+1}^{S} \rho_{s} P_{s}^{F P}(b, a)
\end{aligned}
$$

so

$$
\begin{aligned}
\operatorname{SSA}_{a}^{P}= & \operatorname{SSW}_{a+1}^{P}-\operatorname{SSW}_{a}^{P}=\sum_{s=a+2}^{b} \rho_{s}\left[P_{s}^{P}(a+1)-P_{s}^{P}(a)\right]+ \\
& +\sum_{s=b+1}^{S} \rho_{s}\left[P_{s}^{F P}(b, a+1)-P_{s}^{F P}(b, a)\right]-\rho_{a+1} P_{a+1}^{P}(a)
\end{aligned}
$$

Again, we define $\tau_{a}^{P}=-\mathrm{SSA}_{a}^{P} / W_{a+1}$ as the implicit tax/subsidy on postponing partial retirement from age $a$ to age $a+1$. The $\operatorname{SSA}^{P}$ is positive if the expected present value of the increment in the flow of both partial and full pension benefits, that is if

$$
\sum_{s=a+2}^{b} \rho_{s}\left[P_{s}^{P}(a+1)-P_{s}^{P}(a)\right]+\sum_{s=b+1}^{S} \rho_{s}\left[P_{s}^{F P}(b, a+1)-P_{s}^{F P}(b, a)\right]
$$

is greater than the expected present value of the partial pension benefit foregone, $\rho_{a+1} P_{a+1}^{P}(a)$, by postponing partial retirement one period, from age $a$ to age $a+1$.

2. The peak value (Coile and Gruber 2000) is the maximum difference in SSW between retiring at any future age $h$ and retiring at age $a$. This measure captures the tradeoff between retiring today and working until a period with much higher SSW. This measure assumes a less myopic behaviour by the individual than SSA because it considers the potential gain in SSW resulting from delaying retirement not only 1 year, but also the gains that may be derived from retiring in any subsequent year. Therefore, it takes into account that an additional year of work sustains the option of retiring at an even later date. Note that the peak value is equal to the SSA if the peak of the SSW process is attained with immediate retirement.

(a) in case of full retirement:

$$
\mathrm{PV}_{a}^{F}=\max _{h}\left\{\mathrm{SSW}_{h}^{F}-\mathrm{SSW}_{a}^{F}\right\}, \quad h=a+1, \ldots, R
$$

where $R$ is the maximum full retirement age allowed fixed exogenously.

(b) in case of partial retirement:

$$
\mathrm{PV}_{a}^{P}=\max _{h}\left\{\mathrm{SSW}_{h}^{P}-\mathrm{SSW}_{a}^{P}\right\}, \quad h=a+1, \ldots, b
$$


where $b \leq R$ is the age of full retirement.

3. The delta social security wealth (DSSW) is the difference between SSW in case of partial retirement at age $a$ and SSW in case of full retirement at age $a$

$$
\operatorname{DSSW}_{a}=\operatorname{SSW}_{a}^{P}-\operatorname{SSW}_{a}^{F}
$$

This measure gives us an assessment about how much partial retirement beats full retirement in terms of SSW. It is important to note that the non-applicability of reduction coefficients in case of partial retirement before the age of 65 is a potential source of making this exit route a dominant strategy against early retirement, at least at an early age.

\subsection{Basic assumptions in the calculation of social security incentives}

In order to compute pension rights it is important to know which individuals have started contributing to the system before 1967 because the elegibility requirements up to 64 are different as already mentioned in Sect. 2. An important limitation of the data set used is that only a part of the details describing the relations taking place before 1966 are electronically recorded. Hence, the data set is incomplete in terms of the number of social security relations collected at least for those individuals who started contributing to the system before 1966. Pension rights have been calculated as if all individuals had the condition of membership in a labour mutual society before 1967. The reason is that as we focus on individuals born between 1937 and 1945, in ages ranging from 22 to 30 in 1967, all of them had the potential to have contributed to labour mutual funds that preceded the establishment of the social security system. ${ }^{5}$ The main consequence of this assumption is that for those individuals who started their real contributory life after 1967, the satisfaction of the minimum period of contributions before 64 is not sufficient to claim for an old-age pension. $^{6}$

Calculation of SSW and related incentive measures depends crucially on the following elements: the legislation which applies at each moment in time, the individual history of contributions, the consumer price index, minimum and maximum contribution bases, minimum and maximum retirement pensions and mortality tables.

We presume that, at each age, workers perfectly know the rules governing the social security system and that they perfectly anticipate legislated changes that are known to take effect in the future, e.g. the gradual increment on the number of years of contribution used to compute the regulating base since 1997. To avoid the

\footnotetext{
5 Although the INE (Instituto Nacional de Estadística) does not provide separate data on high level education by age groups, only 147,233 individuals were enrolled in superior studies in 1967. For more details see INE (1968).

6 Although this assumption, we observe 835 individuals who start perceiving a contributory pension and do not satisfy the minimum period of contributions. We decided to eliminate these individuals of the analysis as the available information was not sufficient to calculate their SSW and related incentive measures.
} 
complications due to changes over time in the income tax schedule, we present calculations before income taxes.

Computing social security incentives requires considering forecasts for future contribution bases so we assume that real contribution bases are constant after the last year of observed bases for each individual. To smooth idiosyncratic noise, contribution bases projections are taken as the average of the last 3 years of observed bases as done in Brugiavini et al. (2003).

The age of certain death is fixed to 100 , the most recent available mortality tables for men from INE (Instituto Nacional de Estadística 1999) are used and we assume a time discount factor $\beta$ equal to 0.97 as in Boldrin et al. (2004). As already mentioned, minimum pensions depend on family considerations. We assume that all individuals had a dependent spouse.

To calculate SSW in case of partial retirement we assume, for simplicity, that each individual who partially retires between ages 60 and 65 enters full retirement at 66. An step forward this assumption would be to make this decision endogenous. That is, to consider that the exit route through partial retirement is the result of a joint decision: when partially retire and when exiting completely the labour market through full retirement. We also abstract from a joint choice between partial retirement and postretirement hours of work and consider that partial retirement implies a part-time contract of $15 \%$ of the working day, the minimum permitted by law. In the sample, we observe more than $80 \%$ of individuals who partially retire reducing their working day by the maximum of $85 \%$. As we restrict the analysis of retirement behaviour in ages ranging from 60 to 65 , we consider that the maximum full retirement age allowed is $R=66$.

Tables 8, 9, 10, 11, 12, 13, 14 in Appendix present descriptive statistics (mean, standard deviation and selected percentiles) for the different incentives measures. ${ }^{7}$ As can be seen in Table 10, the mean of $\operatorname{SSA}^{F}$ is positive except for the age of 65. That is, continuing to work at ages 60-64, instead of fully retiring, comes with a gain in terms of SSW. Equivalently, there is an implicit subsidy (negative implicit tax) on postponing 1 year full retirement between 60 and 64, as can be observed in Table 11. On the contrary, at the age of 65 there is an implicit tax on further labour force participation. In the case of partial retirement, the tax on continue working arrives at an earlier age. Moreover, the mean peak value decreases with age and eventually becomes negative both in case of full and partial retirement, as can be seen in Table 12. This means that the gain in terms of SSW resulting from delaying retirement until a period with much higher SSW fades with age, and more rapidly in case of partial retirement. The analysis of the different incentives measures goes in favour of the idea outlined in the introduction: the non-applicability of reduction coefficients in case of partial retirement before the age of 65 is a potential source of making this exit route a dominant strategy against early retirement.

\footnotetext{
7 Additional descriptive statistics are available upon request.
} 


\section{Results}

We estimate the influence of individual and contributory life characteristics and social security incentives on the hazard of entering retirement, either fully or partially. The estimation results are presented in Tables 2, 3, 4, 5, 6, 7 and in Figs. 3, $4,5,6{ }^{8}$ We discuss the qualitative impacts of the variables included in the analysis on the conditional hazard rates by studying the sign and statistical significance of the estimated coefficients. The dependence of the hazard rate on the time spent in a situation of non-retirement is captured through duration dummies, through duration dummies interacted with a dummy variable indicating at each duration if the individual achieved the minimum period of contribution and through the interaction of the explanatory variables with the logarithm of the duration to account for possible different effects of independent variables at different ages. We chose not to restrict the analysis to people who satisfy the minimum period of contributions at the age of 60 , for example, although we control for the satisfaction of this requirement through dummy variables. It is thought that a potentially different behaviour could arise between individuals who are entitled at 60 and individuals who are entitled at 63, due, for example, to the non-linear application of reduction coefficients.

\subsection{The impact of social security wealth and social security accrual}

Table 2 presents the results of the estimation by conditional maximum likelihood. ${ }^{9}$ In addition to personal and contributory life characteristics, in columns $1 \mathrm{a}$ and $1 \mathrm{~b}$ the only regressor introduced capturing social security regulation is social security wealth. In columns $2 \mathrm{a}$ and $2 \mathrm{~b}$, aside from the same variables presented in columns $1 \mathrm{a}$ and $1 \mathrm{~b}$, social security accrual is included. Both specifications are satisfactory in terms of explaining variability in the data measured through the pseudo $R^{2}$ statistic. ${ }^{10}$ The specification with both SSW and SSA is the preferred one. Before analysing the effect of the different variables, it is necessary to point out the important difference in the magnitude and shape of the predicted hazard rates to the two forms of accessing pension benefits, see Figs. 3 and 4.

As it can be seen in columns $2 \mathrm{a}$ and $2 \mathrm{~b}$ of Table 2, each measure of SSW has a significant positive impact on its own hazard rate while a significant negative impact on the hazard rate of the alternative risk. Particularly, the SSW in case of full retirement $\left(\mathrm{SSW}^{F}\right)$ has a positive effect on the hazard rate to full retirement that lessens over time, while a negative one on the hazard rate to partial retirement. The

\footnotetext{
8 The results are robust to the inclusion of measures of business cycle effects (either time dummies or GDP growth). The estimation results are not reported but are available upon request.

9 The conditional maximum likelihood provides consistent and asymptotically normal estimates of the parameters. Moreover, its computation is faster. However, a joint estimation has also been performed, given that the joint estimation of the parameters is asymptotically more efficient. The results obtained by joint maximum likelihood do not significantly differ from the ones obtained by conditional maximum likelihood. The results are available upon request.

10 The pseudo $R^{2}$ in a non-reported model without incentive measures is equal to 0.3520 and 0.2045 in case of full and partial retirement, respectively. Note that there is a substantial increase in this statistic in case of partial retirement when both the social security wealth and the social security accrual are included.
} 
Table 2 Estimates of logistic hazard of entering retirement: full and partial retirement

\begin{tabular}{|c|c|c|c|c|}
\hline Variable & $\begin{array}{l}\text { Full } \\
\text { 1a }\end{array}$ & $\begin{array}{l}\text { Partial } \\
1 \mathrm{~b}\end{array}$ & $\begin{array}{l}\text { Full } \\
2 \mathrm{a}\end{array}$ & $\begin{array}{l}\text { Partial } \\
2 \mathrm{~b}\end{array}$ \\
\hline \multicolumn{5}{|l|}{ Social security incentives } \\
\hline $\mathrm{SSW}^{F}$ & $\begin{array}{l}3.7011 \\
\quad(15.62)^{* * * *}\end{array}$ & $\begin{array}{l}5.8539 \\
\quad(14.10)^{* * * *}\end{array}$ & $\begin{array}{l}11.2934 \\
\quad(31.97)^{* * * *}\end{array}$ & $\begin{array}{l}-7.8446 \\
\quad(5.49)^{* * * *}\end{array}$ \\
\hline $\mathrm{SSW}^{F} \times \log$ Dur & $\begin{array}{r}-0.4085 \\
(1.96)^{*}\end{array}$ & $\begin{array}{l}-4.4272 \\
\quad(8.60)^{* * * *}\end{array}$ & $\begin{array}{l}-5.1010 \\
\quad(19.26)^{* * *}\end{array}$ & $\begin{array}{c}-1.7548 \\
(1.02)\end{array}$ \\
\hline $\mathrm{SSW}^{P}$ & $\begin{array}{l}-5.4748 \\
\quad(51.69)^{* * *}\end{array}$ & $\begin{array}{l}4.2291 \\
\quad(20.76)^{* * *}\end{array}$ & $\begin{array}{l}-6.3314 \\
(46.90)^{* * *}\end{array}$ & $\begin{array}{l}14.2563 \\
\quad(14.63)^{* * * *}\end{array}$ \\
\hline $\mathrm{SSW}^{P} \times \log$ Dur & $\begin{array}{l}1.8828 \\
\quad(16.21)^{* * *}\end{array}$ & $\begin{array}{l}0.6267 \\
\quad(2.10)^{* *}\end{array}$ & $\begin{array}{l}3.1761 \\
\quad(22.12)^{* * *}\end{array}$ & $\begin{array}{c}-2.1808 \\
(1.50)\end{array}$ \\
\hline $\mathrm{SSA}^{F}$ & & & $\begin{array}{l}-52.6813 \\
(28.22)^{* * *}\end{array}$ & $\begin{array}{l}-20.1806 \\
(4.97)^{* * *}\end{array}$ \\
\hline $\operatorname{SSA}^{F} \times \log$ Dur & & & $\begin{array}{l}31.0475 \\
\quad(21.15)^{* * *}\end{array}$ & $\begin{array}{r}0.5969 \\
(0.13)\end{array}$ \\
\hline $\mathrm{SSA}^{P}$ & & & $\begin{array}{l}253.8769 \\
\quad(28.73)^{* * * *}\end{array}$ & $\begin{array}{r}-305.8575 \\
(20.34)^{* * * *}\end{array}$ \\
\hline $\operatorname{SSA}^{P} \times \log$ Dur & & & $\begin{array}{l}-81.9933 \\
(6.30)^{* * * *}\end{array}$ & $\begin{array}{r}-56.2739 \\
(2.17)^{* *}\end{array}$ \\
\hline \multicolumn{5}{|l|}{ Personal characteristics } \\
\hline University education & $\begin{array}{l}-0.4273 \\
\quad(8.23)^{* * * *}\end{array}$ & $\begin{array}{l}-1.9598 \\
\quad(14.86)^{* * * *}\end{array}$ & $\begin{array}{l}-0.4212 \\
\quad(7.26)^{* * * *}\end{array}$ & $\begin{array}{l}-2.0903 \\
\quad(15.60)^{* * * *}\end{array}$ \\
\hline University education $\times \log$ Dur & $\begin{array}{l}-0.2646 \\
\quad(5.43)^{* * * *}\end{array}$ & $\begin{array}{l}0.8127 \\
\quad(4.89)^{* * * *}\end{array}$ & $\begin{array}{l}-0.2532 \\
\quad(4.98)^{* * * *}\end{array}$ & $\begin{array}{l}0.8152 \\
\quad(4.85)^{* * * *}\end{array}$ \\
\hline Foreign & $\begin{array}{l}-1.3176 \\
(5.20)^{* * *}\end{array}$ & $\begin{array}{l}-5.1706 \\
(5.17)^{* * * *}\end{array}$ & $\begin{array}{l}-1.2523 \\
\quad(4.90)^{* * * *}\end{array}$ & $\begin{array}{l}-5.264 \\
\quad(5.26)^{* * * *}\end{array}$ \\
\hline Foreign $\times \log$ Dur & $\begin{array}{l}0.1113 \\
\quad(0.56)\end{array}$ & $\begin{array}{l}1.9949 \\
\quad(9.93)^{* * *} *\end{array}$ & $\begin{array}{r}0.0607 \\
(0.31)\end{array}$ & $\begin{array}{l}2.0043 \\
\quad(9.84)^{* * * *}\end{array}$ \\
\hline Disability pension & $\begin{array}{l}-3.0169 \\
(23.47)^{* * *}\end{array}$ & $\begin{array}{l}-3.3037 \\
\quad(5.48) * * *\end{array}$ & $\begin{array}{l}-2.6738 \\
\quad(20.27)^{* * * *}\end{array}$ & $\begin{array}{l}-3.0347 \\
(4.61)^{* * *}\end{array}$ \\
\hline Disability pension $\times \log$ Dur & $\begin{array}{c}-0.1116 \\
(1.22)\end{array}$ & $\begin{array}{r}0.0526 \\
\quad(0.06)\end{array}$ & $\begin{array}{l}-0.2220 \\
(2.38)^{* *}\end{array}$ & $\begin{array}{r}0.1320 \\
\quad(0.13)\end{array}$ \\
\hline \multicolumn{5}{|l|}{ Contributive life characteristics } \\
\hline Unemployed & $\begin{array}{l}1.4522 \\
\quad(47.46)^{* * * *}\end{array}$ & $\begin{array}{l}-2.5393 \\
\quad(16.05)^{* * *}\end{array}$ & $\begin{array}{l}1.4090 \\
\quad(44.68)^{* * * *}\end{array}$ & $\begin{array}{l}-2.5144 \\
\quad(15.64)^{* * * *}\end{array}$ \\
\hline Unemployed $\times \log$ Dur & $\begin{array}{l}0.1393 \\
\quad(4.36)^{* * * *}\end{array}$ & $\begin{array}{c}-0.3244 \\
(0.86)\end{array}$ & $\begin{array}{l}0.1559 \\
\quad(4.83)^{* * * *}\end{array}$ & $\begin{array}{c}-0.2874 \\
(0.75)\end{array}$ \\
\hline Number of SS relations & $\begin{array}{l}-0.0061 \\
\quad(8.70)^{* * *}\end{array}$ & $\begin{array}{l}0.0173 \\
\quad(7.97)^{* * * *}\end{array}$ & $\begin{array}{l}-0.0063 \\
\quad(8.69) * * *\end{array}$ & $\begin{array}{l}0.0184 \\
\quad(8.24)^{* * * *}\end{array}$ \\
\hline $\begin{array}{l}\text { Number of SS relations } \\
\text { (squared) }\end{array}$ & $\begin{array}{l}0 \\
(7.66) * * *\end{array}$ & $\begin{array}{l}0 \\
(3.83)^{* * * *}\end{array}$ & $\begin{array}{l}0 \\
(7.93)^{* * * *}\end{array}$ & $\begin{array}{l}0 \\
(4.29)^{* * * *}\end{array}$ \\
\hline Unique relation & $\begin{array}{l}-2.2838 \\
(4.88) * * *\end{array}$ & $\begin{array}{l}-1.2220 \\
(4.28)^{* * * *}\end{array}$ & $\begin{array}{l}-2.3649 \\
(4.96)^{* * * *}\end{array}$ & $\begin{array}{l}-0.9975 \\
\quad(3.44)^{* * * *}\end{array}$ \\
\hline Unique relation $\times \log$ Dur & $\begin{array}{l}1.0926 \\
(3.44)^{* * * *}\end{array}$ & $\begin{array}{r}0.5174 \\
(1.25)\end{array}$ & $\begin{array}{l}1.1293 \\
\quad(3.51)^{* * * *}\end{array}$ & $\begin{array}{r}0.4382 \\
(1.06)\end{array}$ \\
\hline $\begin{array}{l}\text { Number of years of } \\
\text { contribution }\end{array}$ & $\begin{array}{c}-0.0043 \\
(1.56)\end{array}$ & $\begin{array}{l}-0.0820 \\
\quad(13.55)^{* * *}\end{array}$ & $\begin{array}{l}0.0084 \\
\quad(2.86)^{* * * *}\end{array}$ & $\begin{array}{l}-0.1002 \\
\quad(15.61)^{* * * *}\end{array}$ \\
\hline
\end{tabular}


Table 2 continued

\begin{tabular}{|c|c|c|c|c|}
\hline Variable & $\begin{array}{l}\text { Full } \\
\text { 1a }\end{array}$ & $\begin{array}{l}\text { Partial } \\
1 \mathrm{~b}\end{array}$ & $\begin{array}{l}\text { Full } \\
2 \mathrm{a}\end{array}$ & $\begin{array}{l}\text { Partial } \\
2 \mathrm{~b}\end{array}$ \\
\hline $\begin{array}{l}\text { Number of years of contribution } \\
\times \log \text { Dur }\end{array}$ & $\begin{array}{l}0.0334 \\
\quad(13.31)^{* * *}\end{array}$ & $\begin{array}{l}0.0173 \\
(2.13)^{* *}\end{array}$ & $\begin{array}{l}0.0245 \\
\quad(9.50)^{* * *}\end{array}$ & $\begin{array}{l}0.0203 \\
\quad(2.45)^{* *}\end{array}$ \\
\hline Agriculture & $\begin{array}{l}0.3777 \\
\quad(7.62) * * *\end{array}$ & $\begin{array}{l}1.1148 \\
\quad(9.27)^{* * * *}\end{array}$ & $\begin{array}{l}0.4311 \\
\quad(8.30)^{* * *}\end{array}$ & $\begin{array}{l}1.0325 \\
(8.12)^{* * * *}\end{array}$ \\
\hline Agriculture $\times \log$ Dur & $\begin{array}{l}0.1459 \\
\quad(3.06)^{* * * *}\end{array}$ & $\begin{array}{l}0.1500 \\
\quad(0.92)\end{array}$ & $\begin{array}{l}0.1162 \\
\quad(2.40)^{* *}\end{array}$ & $\begin{array}{l}0.1457 \\
\quad(0.87)\end{array}$ \\
\hline Industry & $\begin{array}{l}0.0339 \\
(0.98)\end{array}$ & $\begin{array}{l}1.1569 \\
(17.61)^{* * * *}\end{array}$ & $\begin{array}{l}0.1055 \\
\quad(2.89)^{* * * *}\end{array}$ & $\begin{array}{l}1.2205 \\
(17.94)^{* * * *}\end{array}$ \\
\hline Industry $\times \log$ Dur & $\begin{array}{l}0.1078 \\
\quad(2.94) * * *\end{array}$ & $\begin{array}{c}-0.0341 \\
(0.34)\end{array}$ & $\begin{array}{l}0.0611 \\
\quad(1.65)^{*}\end{array}$ & $\begin{array}{c}-0.0008 \\
(0.01)\end{array}$ \\
\hline Construction & $\begin{aligned}- & 0.2422 \\
& (5.02)^{* * * *}\end{aligned}$ & $\begin{array}{l}-0.8731 \\
\quad(5.45)^{* * * *}\end{array}$ & $\begin{array}{l}-0.2912 \\
\quad(5.78)^{* * * *}\end{array}$ & $\begin{array}{l}-0.7886 \\
(4.97)^{* * * *}\end{array}$ \\
\hline Construction $\times \log$ Dur & $\begin{array}{l}0.2155 \\
\quad(4.40) * * *\end{array}$ & $\begin{array}{l}0.4930 \\
\quad(2.41)^{* *}\end{array}$ & $\begin{array}{l}0.2519 \\
\quad(5.09) * * *\end{array}$ & $\begin{array}{l}0.4817 \\
\quad(2.37)^{* *}\end{array}$ \\
\hline General system & $\begin{array}{l}0.5799 \\
\quad(6.43) * * *\end{array}$ & $\begin{array}{l}3.1735 \\
\quad(5.64) * * *\end{array}$ & $\begin{array}{l}0.9639 \\
\quad(10.54)^{* * * *}\end{array}$ & $\begin{array}{l}3.2208 \\
\quad(5.66) * * *\end{array}$ \\
\hline General system $\times \log$ Dur & $\begin{array}{l}0.2446 \\
\quad(3.03) * * *\end{array}$ & $\begin{array}{r}0.4253 \\
(0.67)\end{array}$ & $\begin{array}{l}0.0223 \\
\quad(0.28)\end{array}$ & $\begin{array}{l}0.4205 \\
\quad(0.64)\end{array}$ \\
\hline Self-employed & $\begin{array}{l}-0.2717 \\
\quad(3.01)^{* * * *}\end{array}$ & $\begin{array}{r}0.6759 \\
(1.15)\end{array}$ & $\begin{array}{l}-0.2537 \\
\quad(2.92)^{* * *}\end{array}$ & $\begin{array}{r}0.7699 \\
(1.30)\end{array}$ \\
\hline Self-employed $\times \log$ Dur & $\begin{array}{l}0.2203 \\
\quad(2.95) * * *\end{array}$ & $\begin{array}{r}0.7852 \\
\quad(1.19)\end{array}$ & $\begin{array}{l}0.2034 \\
\quad(2.77)^{* * *}\end{array}$ & $\begin{array}{r}0.8215 \\
\quad(1.21)\end{array}$ \\
\hline Special agricultural system & $\begin{array}{l}-0.4642 \\
(4.70) * * *\end{array}$ & $\begin{array}{c}-0.4802 \\
(0.63)\end{array}$ & $\begin{array}{l}-0.5293 \\
\quad(5.63) * * *\end{array}$ & $\begin{array}{c}-0.3726 \\
(0.47)\end{array}$ \\
\hline $\begin{array}{l}\text { Special agricultural system } \times \\
\log \text { Dur }\end{array}$ & $\begin{array}{c}-0.0429 \\
(0.54)\end{array}$ & $\begin{array}{l}1.7846 \\
(2.38)^{* *}\end{array}$ & $\begin{array}{c}-0.0036 \\
(0.05)\end{array}$ & $\begin{array}{l}1.7381 \\
(2.20)^{* *}\end{array}$ \\
\hline \multicolumn{5}{|l|}{ Duration variables } \\
\hline Constant & $\begin{array}{l}-3.1986 \\
\quad(24.55)^{* * *}\end{array}$ & $\begin{array}{l}-4.9587 \\
(8.78)^{* * * *}\end{array}$ & $\begin{array}{l}-3.6240 \\
\quad(27.30)^{* * *}\end{array}$ & $\begin{array}{l}-4.8966 \\
(8.58)^{* * *}\end{array}$ \\
\hline d60 $\times$ eligibility & $\begin{array}{l}1.2154 \\
\quad(11.04)^{* * *}\end{array}$ & $\begin{array}{l}-1.7121 \\
\quad(10.52)^{* * *}\end{array}$ & $\begin{array}{l}0.4542 \\
\quad(4.01)^{* * * *}\end{array}$ & $\begin{array}{l}-1.0677 \\
(5.95)^{* * *}\end{array}$ \\
\hline $\mathrm{d} 61$ & $\begin{array}{l}-1.6041 \\
(7.36)^{* * *}\end{array}$ & $\begin{array}{l}-1.8236 \\
(3.65)^{* * *}\end{array}$ & $\begin{array}{l}-1.4202 \\
(6.50)^{* * * *}\end{array}$ & $\begin{array}{l}-1.8444 \\
(3.62)^{* * *}\end{array}$ \\
\hline d61 $\times$ eligibility & $\begin{array}{l}0.4260 \\
\quad(2.16)^{* *}\end{array}$ & $\begin{array}{l}-1.1192 \\
(4.37)^{* * *}\end{array}$ & $\begin{array}{r}0.0302 \\
\quad(0.15)\end{array}$ & $\begin{array}{l}-0.6301 \\
(2.38)^{* *}\end{array}$ \\
\hline d62 & $\begin{array}{l}-1.9287 \\
(7.33)^{* * *}\end{array}$ & $\begin{array}{c}-1.6655 \\
(2.28)^{* *}\end{array}$ & $\begin{array}{l}-1.6379 \\
(6.21)^{* * *}\end{array}$ & $\begin{array}{l}-1.6912 \\
(2.26)^{* *}\end{array}$ \\
\hline d62 $\times$ eligibility & $\begin{array}{r}0.2555 \\
\quad(1.08)\end{array}$ & $\begin{array}{l}-1.3125 \\
(4.86)^{* * *}\end{array}$ & $\begin{array}{c}-0.0228 \\
(0.10)\end{array}$ & $\begin{array}{r}-0.6820 \\
(2.47)^{* *}\end{array}$ \\
\hline d63 & $\begin{array}{l}-2.2146 \\
(7.01)^{* * * *}\end{array}$ & $\begin{array}{l}-3.1599 \\
(3.18)^{* * *}\end{array}$ & $\begin{array}{l}-1.8487 \\
\quad(5.84)^{* * * *}\end{array}$ & $\begin{array}{l}-3.1848 \\
(3.14)^{* * *}\end{array}$ \\
\hline d63 $\times$ eligibility & $\begin{array}{l}0.1915 \\
\quad(0.66)\end{array}$ & $\begin{array}{c}-0.2848 \\
(0.56)\end{array}$ & $\begin{array}{r}0.1814 \\
\quad(0.62)\end{array}$ & $\begin{array}{l}0.6480 \\
\quad(1.27)\end{array}$ \\
\hline d64 & $\begin{array}{l}-2.1179 \\
(6.12)^{* * *}\end{array}$ & $\begin{array}{l}-3.5057 \\
(2.97)^{* * *}\end{array}$ & $\begin{array}{l}-1.6923 \\
(4.88)^{* * *}\end{array}$ & $\begin{array}{l}-3.5389 \\
(2.94)^{* * *}\end{array}$ \\
\hline
\end{tabular}


Table 2 continued

\begin{tabular}{|c|c|c|c|c|}
\hline Variable & $\begin{array}{l}\text { Full } \\
\text { 1a }\end{array}$ & $\begin{array}{l}\text { Partial } \\
1 \mathrm{~b}\end{array}$ & $\begin{array}{l}\text { Full } \\
2 \mathrm{a}\end{array}$ & $\begin{array}{l}\text { Partial } \\
2 b\end{array}$ \\
\hline d64 $\times$ eligibility & $\begin{array}{l}0.4481 \\
\quad(1.44)\end{array}$ & $\begin{array}{c}-1.1182 \\
(1.64)\end{array}$ & $\begin{array}{l}0.4079 \\
\quad(1.31)\end{array}$ & $\begin{array}{c}-0.6332 \\
(0.91)\end{array}$ \\
\hline d65 & $\begin{array}{l}1.5780 \\
\quad(7.53)^{* * * *}\end{array}$ & $\begin{array}{l}-3.3256 \\
(2.63)^{* * * *}\end{array}$ & $\begin{array}{l}2.0461 \\
\quad(9.71)^{* * * *}\end{array}$ & $\begin{array}{l}-3.3565 \\
(2.60)^{* * * *}\end{array}$ \\
\hline d65 $\times$ eligibility & $\begin{array}{l}0.3521 \\
(2.49)^{* *}\end{array}$ & $\begin{array}{c}-0.0378 \\
(0.06)\end{array}$ & $\begin{array}{l}0.4930 \\
\quad(3.49)^{* * * *}\end{array}$ & $\begin{array}{l}0.3143 \\
\quad(0.45)\end{array}$ \\
\hline Pseudo $R^{2}$ & 0.3788 & 0.2459 & 0.3953 & 0.3093 \\
\hline Log likelihood & $-37,558$ & $-8,317$ & $-36,558$ & $-7,618$ \\
\hline
\end{tabular}

$t$ ratios in parentheses: *significant at $10 \%$; * significant at $5 \%$; ***significant at $1 \%$. Monetary values are in millions euros

Table 3 Marginal effects on transition intensities and percentage of change in transition intensities

\begin{tabular}{|c|c|c|c|c|c|c|c|c|}
\hline \multirow[t]{3}{*}{ Age } & \multicolumn{4}{|c|}{ Marginal effects of } & \multicolumn{4}{|c|}{ Percentage of change } \\
\hline & \multicolumn{2}{|l|}{$\mathrm{SSW}^{F}$} & \multicolumn{2}{|l|}{$\mathrm{SSW}^{P}$} & \multicolumn{2}{|c|}{$\mathrm{SSW}^{F}$} & \multicolumn{2}{|l|}{$\mathrm{SSW}^{P}$} \\
\hline & Full & Partial & Full & Partial & Full & Partial & Full & Partial \\
\hline 60 & 0.0181 & -0.0037 & -0.0085 & 0.0100 & 10.82 & -14.15 & -5.10 & 38.24 \\
\hline 61 & 0.0058 & -0.0020 & -0.0022 & 0.0039 & 12.37 & -20.03 & -4.79 & 38.16 \\
\hline 62 & 0.0059 & -0.0021 & -0.0021 & 0.0031 & 10.01 & -21.40 & -3.54 & 31.68 \\
\hline 63 & 0.0053 & -0.0013 & -0.0018 & 0.0016 & 7.90 & -25.00 & -2.65 & 30.50 \\
\hline 64 & 0.0073 & -0.0004 & -0.0021 & 0.0004 & 5.54 & -27.21 & -1.57 & 26.50 \\
\hline 65 & 0.0066 & -0.0003 & -0.0016 & 0.0002 & 0.90 & -27.71 & -0.22 & 23.43 \\
\hline
\end{tabular}

For computing marginal effects, we evaluate the marginal effects at every observation the sample average of the individual marginal effects. The marginal effect is measured by the increment that each variable is going to experiment if all pensions benefits increase in $10 \%$, holding the rest of the variables constant

$\mathrm{SSW}^{P}$ has a positive impact on the hazard rate to partial retirement while a negative one, that lessens over time, on the hazard rate to full retirement. The estimators all have the expected sign and are statistically significant. An increase in SSW could be interpreted as a wealth effect, so as an incentive to increase the consumption of leisure, which requires retiring earlier. It is interesting to notice the negative sign that each measure of SSW has on the alternative exit route. We could interpret this finding in the following sense: if partial pensions are favoured, and hence $\mathrm{SSW}^{P}$ is increased, this will imply a reduction on the hazard rate to full retirement and a rise on the hazard rate to partial retirement, other things equal.

With respect to the first incentive measure and for the case of full retirement, $\mathrm{SSA}^{F}$ affects negatively the hazard rate to full retirement, as expected. The larger the $\mathrm{SSA}^{F}$, the less the individual brings forward full retirement. It must be noted that the negative impact of $\mathrm{SSA}^{F}$ on the hazard rate to full retirement becomes positive at 65 years of age. That is, at the age of 65 the increase in $\mathrm{SSW}^{F}$ one can obtain by postponing 1 year full retirement has a positive impact on its own hazard rate. Even if the postponement of full retirement is awarded through greater $\mathrm{SSA}^{F}$, there exists a 
Table 4 Estimates of logistic hazard of entering retirement: full and partial retirement

\begin{tabular}{|c|c|c|}
\hline Variable & $\begin{array}{l}\text { Full } \\
\text { 1a }\end{array}$ & $\begin{array}{l}\text { Partial } \\
1 \mathrm{~b}\end{array}$ \\
\hline \multicolumn{3}{|c|}{ Social security incentives } \\
\hline $\mathrm{SSW}^{F}$ & $6.0587(23.17)^{* * *}$ & $-0.0640(0.08)$ \\
\hline $\mathrm{SSW}^{F} \times \log$ Dur & $-2.1142(9.55)^{* * *}$ & $-1.5787(2.00)^{* *}$ \\
\hline $\mathrm{SSW}^{P}$ & $-6.9708(53.81)^{* * * *}$ & $8.9898(16.82)^{* * *}$ \\
\hline $\mathrm{SSW}^{P} \times \log$ Dur & $3.3444(25.21)^{* * *}$ & $-1.6782(3.11)^{* * *}$ \\
\hline$\tau^{F}$ & $0.0443(2.49)^{* *}$ & $1.1359(17.68)^{* * *}$ \\
\hline$\tau^{F} \times \log$ Dur & $-0.0675(4.21)^{* * *}$ & $-0.3907(7.29)^{* * *}$ \\
\hline$\tau^{P}$ & $-3.5433(36.64) * * *$ & $3.4093(19.72)^{* * *}$ \\
\hline$\tau^{P} \times \log$ Dur & $0.9451(5.22)^{* * *}$ & $-1.1618(5.60)^{* * *}$ \\
\hline Pseudo $R^{2}$ & 0.4062 & 0.2985 \\
\hline Log likelihood & $-35,649$ & $-7,724$ \\
\hline Variable & $\begin{array}{l}\text { Full } \\
2 \mathrm{a}\end{array}$ & $\begin{array}{l}\text { Partial } \\
2 b\end{array}$ \\
\hline \multicolumn{3}{|c|}{ Social security incentives } \\
\hline $\mathrm{SSW}^{F}$ & $1.1794(3.74)^{* * *}$ & $-32.0198(6.92)^{* * *}$ \\
\hline $\mathrm{SSW}^{F} \times \log$ Dur & $0.8109(3.23)^{* * *}$ & $14.1701(4.99)^{* * *}$ \\
\hline $\mathrm{SSW}^{P}$ & $-8.0679(55.46)^{* * *}$ & $37.7482(8.78)^{* * *}$ \\
\hline $\mathrm{SSW}^{P} \times \log$ Dur & $4.0137(27.97)^{* * *}$ & $-18.5031(7.00)^{* * *}$ \\
\hline $\mathrm{PV}^{F}$ & $11.2700(26.56)^{* * *}$ & $-29.7299(7.19)^{* * *}$ \\
\hline $\mathrm{PV}^{F} \times \log$ Dur & $4.9053(7.55)^{* * *}$ & $17.8500(5.07)^{* * *}$ \\
\hline $\mathrm{PV}^{P}$ & $129.8351(36.03)^{* * *}$ & $-176.4623(10.98)^{* * * *}$ \\
\hline $\mathrm{PV}^{P} \times \log$ Dur & $-49.6167(5.23) * * *$ & $-189.8836(6.53)^{* * *}$ \\
\hline Pseudo $R^{2}$ & 0.4234 & 0.2977 \\
\hline Log likelihood & $-34,860$ & $-7,746$ \\
\hline
\end{tabular}

$t$ ratios in parentheses: $*$ significant at $10 \% ; * *$ significant at $5 \%$; *** significant at $1 \%$. Monetary values are in millions euros

reluctance to remain in the labour market at the age of 65 . In relation to the $\operatorname{SSA}^{P}$ it influences the hazard rate to partial retirement negatively, as expected.

Since the coefficients from a non-linear model do not have an immediate interpretation in terms of magnitude, we provide in Table 3 the marginal effect that each SSW has on transition intensities at each age. We evaluate the marginal effects at every observation and use the sample average of the individual marginal effects. We measure the marginal effect by the increment that each variable is going to experiment if all pension benefits increase in $10 \%$, holding the rest of the variables constant. Due to the large differences in the magnitude of the hazard rates to the two types of exit routes, it is necessary to evaluate these effects not only in absolute but also in relative terms, therefore the percentage of change in transition intensities is also reported. It can be seen in Table 3 that, for the same increment in pensions, transition intensities to partial retirement are more responsive to its own SSW than the corresponding ones to full retirement. 
Table 5 Estimates of logistic hazard of entering retirement: full and partial retirement

\begin{tabular}{|c|c|c|c|c|}
\hline Variable & $\begin{array}{l}\text { Full } \\
\text { 1a }\end{array}$ & $\begin{array}{l}\text { Partial } \\
1 \mathrm{~b}\end{array}$ & $\begin{array}{l}\text { Full } \\
2 \mathrm{a}\end{array}$ & $\begin{array}{l}\text { Partial } \\
2 \mathrm{~b}\end{array}$ \\
\hline \multicolumn{5}{|c|}{ Social security incentives } \\
\hline DSSW & $\begin{array}{l}-9.4799 \\
\quad(33.82)^{* * * *}\end{array}$ & $\begin{array}{l}8.6708 \\
\quad(15.24)^{* * * *}\end{array}$ & $\begin{array}{l}-12.8517 \\
\quad(32.73)^{* * * *}\end{array}$ & $\begin{array}{l}20.8712 \\
\quad(23.48)^{* * * *}\end{array}$ \\
\hline DSSW $\times \log$ Dur & $\begin{array}{l}1.0849 \\
(1.88)^{*}\end{array}$ & $\begin{array}{l}-6.0932 \\
(4.67)^{* * * *}\end{array}$ & $\begin{array}{l}2.5868 \\
(3.82) * * *\end{array}$ & $\begin{array}{r}-3.5097 \\
(1.80)^{*}\end{array}$ \\
\hline $\mathrm{SSA}^{F}$ & & & $\begin{array}{r}-12.6872 \\
(9.95)^{* * *}\end{array}$ & $\begin{array}{l}-8.5174 \\
(2.83)^{* * *}\end{array}$ \\
\hline $\operatorname{SSA}^{F} \mathrm{x} \log$ Dur & & & $\begin{array}{l}11.3086 \\
(8.83)^{* * *}\end{array}$ & $\begin{array}{r}-7.5618 \\
(1.88)^{*}\end{array}$ \\
\hline $\mathrm{SSA}^{P}$ & & & $\begin{array}{l}209.9583 \\
\quad(22.56)^{* * * *}\end{array}$ & $\begin{array}{r}-386.4795 \\
(31.93) * * *\end{array}$ \\
\hline $\mathrm{SSA}^{P} \times \log$ Dur & & & $\begin{array}{l}-41.4675 \\
(3.61)^{* * * *}\end{array}$ & $\begin{array}{r}-46.4764 \\
(2.34)^{* *}\end{array}$ \\
\hline Pseudo $R^{2}$ & 0.3592 & 0.2132 & 0.3702 & 0.3029 \\
\hline Log likelihood & $-38,742$ & $-8,677$ & $-38,077$ & $-7,688$ \\
\hline
\end{tabular}

$t$ ratios in parentheses: * significant at $10 \%$; * significant at $5 \%$; *** significant at $1 \%$. Monetary values are in millions euros

Table 6 Marginal effects of DSSW on transition intensities and percentage of change in transition intensities

\begin{tabular}{|c|c|c|c|c|}
\hline \multirow[t]{2}{*}{ Age } & \multicolumn{2}{|c|}{ Marginal effects } & \multicolumn{2}{|c|}{ Percentage of change } \\
\hline & Full & Partial & Full & Partial \\
\hline 60 & 0.0144 & -0.0140 & 8.63 & -53.40 \\
\hline 61 & 0.0037 & -0.0038 & 7.85 & -36.89 \\
\hline 62 & 0.0027 & -0.0018 & 4.57 & -18.57 \\
\hline 63 & 0.0016 & -0.0005 & 2.35 & -8.81 \\
\hline 64 & 0.0009 & 0.0000 & 0.68 & -2.34 \\
\hline
\end{tabular}

For computing marginal effects, we evaluate the marginal effects at every observation and use the sample average of the individual marginal effects. We measure the marginal effect by the decrease that DSSW is going to suffer if reduction coefficients also affect pensions stemming from partial retirement before reaching the age of 65

Concerning the other regressors included in Table 2, and aside from social security incentives, our results show that having a high level of education, approximated by the job qualification, affects the hazard rate to both types of routes negatively. Figures 5 and 6 illustrate this result. This is a recurrent finding in empirical studies of retirement behaviour, as also found in Blanco (2000) where individuals with a high qualification try to delay the date of retirement. It is surprising the negative effect that perceiving a disability pension has on the hazard rate to both types of risks. The explanation for this counterintuitive sign is the legislation itself, which states that disability pensions will become retirement pensions once the 
Table 7 Probability of full retirement as second-best given partial retirement as first choice

\begin{tabular}{lr}
\hline Age & $\%$ \\
\hline 60 & 5.11 \\
61 & 2.00 \\
62 & 3.10 \\
63 & 4.34 \\
64 & 8.85 \\
65 & 68.18 \\
\hline
\end{tabular}

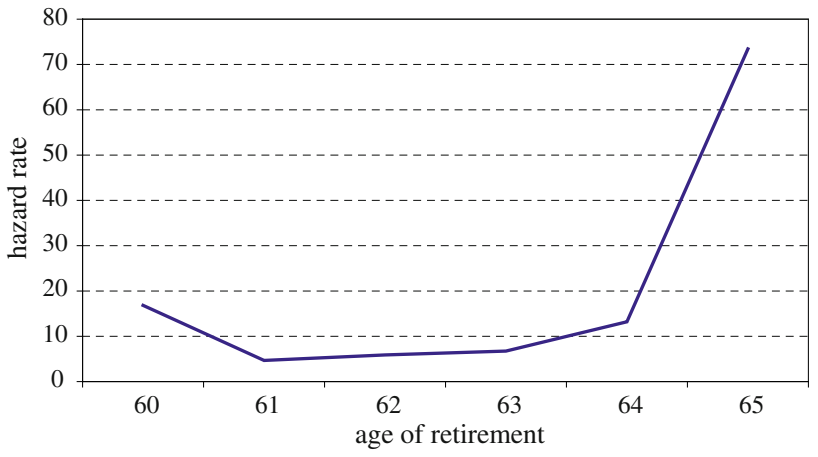

Fig. 3 Predicted hazard rate to full retirement

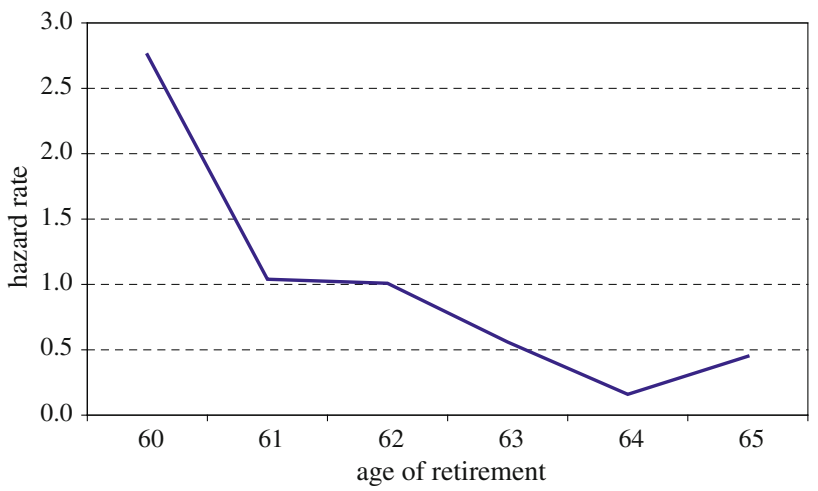

Fig. 4 Predicted hazard rate to partial retirement

beneficiaries turn 65 years of age. ${ }^{11}$ We finally notice which variables have a differential impact on the hazard rates to both types of risks. In particular, both perceiving an unemployment benefit and the number of years of contribution to the

\footnotetext{
11 If individuals who perceive disability pensions do not retire until they reach 65 the new pension denomination does not imply any modifications to the pensions that have been received up to that point.
} 


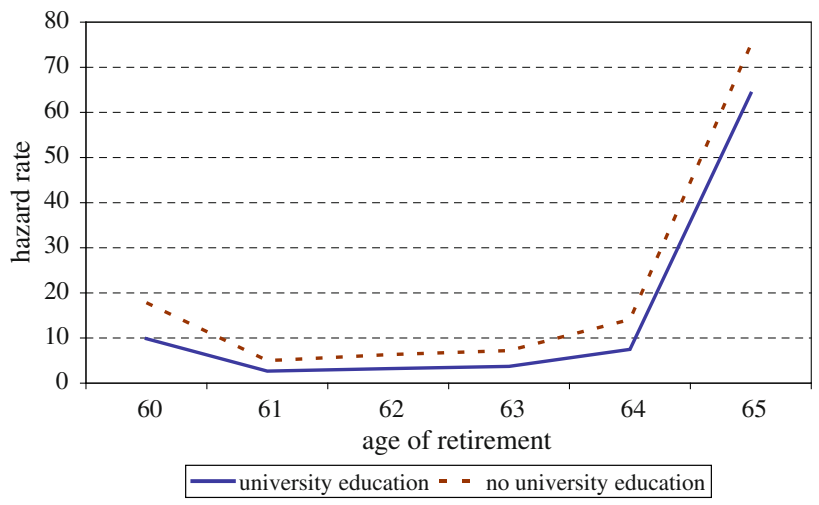

Fig. 5 Predicted hazard rate to full retirement by level of education

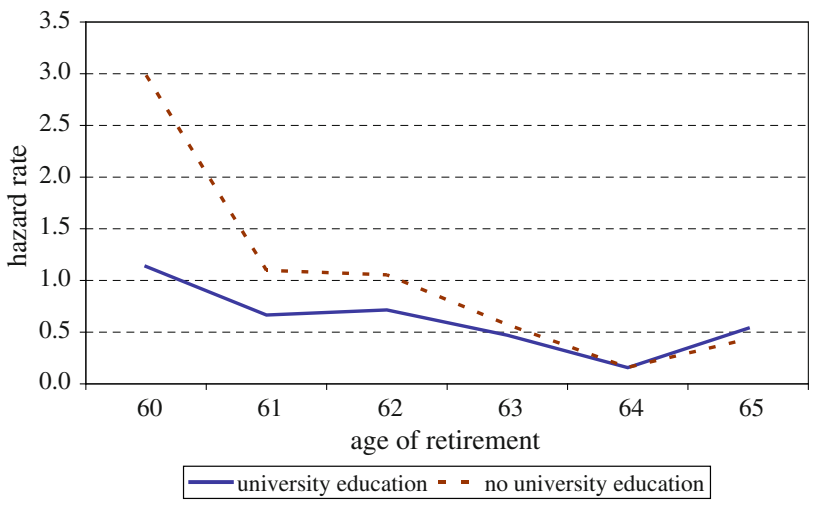

Fig. 6 Predicted hazard rate to partial retirement by level of education

system have a negative effect on the hazard rate to partial retirement while a positive effect on the hazard rate to full retirement.

5.2 The impact of the implicit tax rate and the peak value

We proceed to analyze the impact of two more incentive measures, namely the implicit tax rate on postponing retirement and the peak value, on the hazard of entering retirement either fully or partially. Table 4 reports the estimates of the same model as columns $2 \mathrm{a}$ and $2 \mathrm{~b}$ in Table 2 but instead of using the social security accrual we use the implicit tax rate in columns $1 \mathrm{a}$ and $1 \mathrm{~b}$ and the peak value in columns $2 \mathrm{a}$ and $2 \mathrm{~b}$ as incentive measures. Only the estimates for the social security measures are presented given that no substantial changes are observed on the rest of variables.

With respect to the implicit tax/subsidy rate imposed by the social security system we observe in columns $1 \mathrm{a}$ and $1 \mathrm{~b}$ of Table 4 that both $\tau^{F}$ and $\tau^{P}$ have a significant expected positive sign on their own hazard rate. However, in case of full retirement this positive effect lessens quickly over time, becoming negative after the age of 61 . 
In relation to the peak value, we observe in columns $2 \mathrm{a}$ and $2 \mathrm{~b}$ of Table 4 that $\mathrm{PV}^{F}$ has an unexpected positive sign to the hazard rate to full retirement while $\mathrm{PV}^{P}$ has the expected negative sign to the hazard rate to partial retirement. These findings suggest that forward-looking measures of economic incentives do influence retirement decisions but only in the case of partial retirement. So, full retirement decisions could be postponed 1 year but no more than this. However, the assumption that the maximum full retirement age allowed is 66 could reduce the potential strength of the peak value as an incentive measure.

\subsection{The impact of delta social security wealth}

To properly evaluate how social security incentives affect the choice between alternative retirement routes we study the impact that delta social security wealth has on each hazard rate. Remember from Sect. 4.2 that this incentive measure provides an assessment about how much partial retirement exceeds full retirement in terms of SSW. Table 5 reports the results of the estimation where we only include as social security incentives the DSSW and the SSA. As we can observe, the DSSW has the expected sign and its coefficient is statistically significant. DSSW affects negatively the hazard rate to full retirement and positively the hazard rate to partial retirement.

The finding that there is variation in the impact of the variable DSSW across risks is important. One implication is that policies designed to increase the DSSW will have the effect of increasing the hazard rate to partial retirement while decreasing the hazard rate to full retirement.

In order to assess the magnitude of the effect of DSSW we use the estimation results presented in columns $2 \mathrm{a}$ and $2 \mathrm{~b}$ of Table 5 and imagine a counterfactual scenario where partial pensions are subject to the application of reduction coefficients in case the worker partially retires before reaching the age of 65 . With this hypothetical policy design we are eliminating one of the major appeals of partial retirement legislation. We provide in Table 6 the marginal effects that DSSW has on transition intensities at each duration. We again evaluate the marginal effects at every observation and use the sample average of the individual marginal effects. We measure the marginal effect by the decrease that DSSW is going to suffer if reduction coefficients also affect pensions stemming from partial retirement before reaching the ordinary age of retirement. Table 14 in Appendix presents descriptive statistics for this relevant difference in DSSW. As we want to evaluate these effects not only in absolute but also in relative terms, we include the percentage of change that transition intensities will experiment at each age as a result of reducing DSSW. As it can be seen in Table 6, the decreasing in the transition intensities to partial retirement are quite substantial. The main effect is observed at the age of 60, the first time partial retirement is allowed and the age when the application of reduction coefficients is more severe. At this age, the probability to partially retire would be reduced by $50 \%$ or more if partial pensions were penalized. Thus, the non-applicability of reduction coefficients in case of partial retirement before the ordinary age of retirement is one of the main determinants of the use of this figure.

To sum up, these results evidence that social security incentives do affect the choice between the use of partial and full retirement as alternative routes to enter 
retirement. If partial retirement is favoured to the detriment of full retirement in terms of increasing the variable DSSW, the selection of retirement routes by the elderly will be influenced. Consequently, there is scope for policy intervention to affect individual retirement decisions.

\subsection{Estimating probabilities of second-best alternatives}

In order to evaluate the impact of partial retirement legislation on the age of retirement, we would like to know which is the second-best alternative for individuals who partially retire, whether it is full retirement or continue in the labour market.

Let us recover the exit indicators at $t$ introduced in Sect. 3

$$
\begin{aligned}
& Y_{F t}=\mathbf{1}\left(T=t, D_{F}=1\right) \\
& Y_{P t}=\mathbf{1}\left(T=t, D_{P}=1\right)
\end{aligned}
$$

and define $Y_{N R t}=1-Y_{P t}-Y_{F t}$ as an indicator of no retirement at $t$. Following Arellano and Zamarro (2007) and letting $u_{j}=x^{\prime} \bar{\beta}_{j}+\varepsilon_{j}$ denote the net utility of alternative $j$, where $j=\{F, P, N R\}$, the probability of alternative $F$ as a secondbest, having alternative $P$ as a first best at $t$, is in general

$$
\begin{aligned}
& \operatorname{Pr}\left(u_{F t}>u_{N R t} \mid u_{P t}>u_{N R t}, u_{P t}>u_{F t}, x, T \geq t\right) \\
& =\frac{\operatorname{Pr}\left(u_{F t}>u_{N R t} \mid x, T \geq t\right)-\operatorname{Pr}\left(Y_{F t}=1 \mid x, T \geq t\right)}{\operatorname{Pr}\left(Y_{P t}=1 \mid x, T \geq t\right)}
\end{aligned}
$$

However, for multinomial logit this reduces to

$$
\begin{aligned}
\operatorname{Pr}\left(u_{F t}\right. & \left.>u_{N R t} \mid u_{P t}>u_{N R t}, u_{P t}>u_{F t}, x, T \geq t\right) \\
& =\operatorname{Pr}\left(u_{F t}>u_{N R t} \mid x, T \geq t\right)=\frac{e^{x^{\prime} \beta_{F}}}{1+e^{x^{\prime} \beta_{F}}}
\end{aligned}
$$

As our objective is to obtain aggregate probabilities of having full retirement as a second best alternative for individuals who choose partial retirement, we take into account the distribution of characteristics given the retirement route chosen and proceed in the following way for every $t$

$$
\begin{aligned}
\operatorname{Pr}\left(u_{F t}\right. & \left.>u_{N R t} \mid Y_{P t}=1, T \geq t\right)=\int \frac{e^{x^{\prime} \beta_{F}}}{1+e^{x^{\prime} \beta_{F}}} \mathrm{~d} F\left(x \mid Y_{P t}=1, T \geq t\right) \\
& =\frac{1}{\operatorname{Pr}\left(Y_{P t}=1 \mid T \geq t\right)} \int \frac{e^{x^{\prime} \beta_{F}}}{1+e^{x^{\prime} \beta_{F}}} \operatorname{Pr}\left(Y_{P t}=1 \mid x, T \geq t\right) \mathrm{d} F(x)
\end{aligned}
$$

or

$$
\operatorname{Pr}\left(u_{F t}>u_{N R t} \mid Y_{P t}=1, T \geq t\right)=\frac{E\left[\frac{e^{x^{\prime} \beta_{F}}}{1+e^{x^{\prime} \beta_{F}}} \frac{e^{x^{\prime} \beta_{P}}}{\left.1+e^{x^{\prime} \beta_{F}+e^{x^{\prime} \beta_{P}}}\right]}\right.}{E\left[\frac{e^{x^{\prime} \beta_{P}}}{1+e^{x^{\prime} \beta_{F}}+e^{x^{\prime} \beta_{P}}}\right]}
$$

In a restrictive partial equilibrium analysis, observing a value of $\operatorname{Pr}\left(u_{F t}>u_{N R t}\right.$ । $Y_{P t}=1, T \geq t$ ) close to one would imply that the partial retirement legislation does 
not create distortions in terms of bringing forward the age of retirement. If, on the contrary, $\operatorname{Pr}\left(u_{F t}>u_{N R t} \mid Y_{P t}=1, T \geq t\right)$ is close to zero, partial retirement legislation modifies the age of retirement, moving it to an earlier date.

Based on the estimated model from columns $2 \mathrm{a}$ and $2 \mathrm{~b}$ of Table 2, Table 7 presents the estimates of the conditional probability of full retirement as a secondbest given partial retirement as the first best separately by ages. Given that in ages ranging from 60 to 63 these probabilities are quite small, we have some evidence that partial retirement legislation has modified the age of retirement, particularly moving it forward. In other words, people who partially retire before the ordinary age of retirement would prefer to continue in the labour market rather than entering full retirement as a second-best option.

\section{Conclusions}

In several developed countries, the ageing process of the population and the shortening of professional lifes may pose fiscal risks to the pay-as-you-go systems of public pensions. For this reason, it is important to understand which factors influence retirement decisions. This paper studies the determinants of two forms of accessing pension benefits, partial and full retirement, by men in ages ranging from 60 to 65 in Spain. A multinomial logit duration model is estimated using the newly released Continuous Sample of Working Histories (Muestra Continua de Vidas Laborales). Different measures capturing the economic incentives of the social security system are constructed with the objective of assessing their explanatory power of retirement decisions. Special interest is devoted to know if partial retirement legislation modifies retirement patterns.

The results show that social security legislation significantly influences retirement behaviour. Thus, individuals seem to behave rationally and in the expected direction to the economic incentives embedded in the social security system. Both the social security wealth and related economic incentives used in the analysis have a significant and in no way negligible effect on the hazard rate to the two types of retirement routes.

Moreover, we find that partial retirement legislation affects the choice between the use of partial and full retirement as alternative forms of accessing old-age pensions. We also find that there is variation across risks in the impact of an incentive variable measuring how much partial retirement beats full retirement in terms of social security wealth. Our results support the idea that there is scope for policy intervention to affect individual retirement decisions. The selection of retirement routes by the elderly will be influenced if partial retirement is favoured to the detriment of full retirement. In particular, the non-applicability of reduction coefficients in case of partial retirement is one of the main determinants of the use of this figure. In fact, we estimate that the probability to partially retire at the age of 60 would be reduced by $50 \%$ or more if partial pensions were penalized through reduction coefficients. 
Furthermore, we have gathered evidence that partial retirement legislation has modified the age of retirement, particularly moving it to an earlier date. Thus, partial retirement is actually creating incentives to advance retirement.

Finally, the results of this paper illustrate that adequate policies to retain old workers at work will only be appropriately formulated once the determinants of retirement decisions are well understood. This paper represents a first attempt to analyze partial retirement legislation in Spain, which can be enriched in different ways. For example, partial retirement could be modelled following an equilibrium search approach, with firms playing a central role. Moreover, partial retirement decisions could be studied in a household framework. It would also be interesting to consider partial retirement as the result of a joint decision: when partially retire and when exiting completely the labour market through full retirement. Finally, the interaction between the tax system and the social security incentives is certainly a recommended topic for further research.

Acknowledgments This paper is dedicated to my family. I gratefully acknowledge the suggestions made by Pedro Mira, Sergi Jiménez, the editor and three anonymous referees, which have improved this work with respect to its initial version. Special thanks are due to Isabel Argimón for her excellent guidance and for her infinite enthusiasm.

\section{Appendix: Data and variables}

Definition of variables used in the empirical analysis:

- Personal characteristics:

- University education ${ }_{i}$ : Proxy for the level of education. Dummy variable that takes the value 1 if the maximum contributory group achieved throughout the worker's career is the number 1, corresponding to engineers and university graduates, according to the legislation. The poor reliability for the educational attainment data obliged us to use a proxy for the level of education using the information on the contributory group.

- Foreign ${ }_{i}$ : Dummy variable that takes the value 1 if the individual nationality is not spanish.

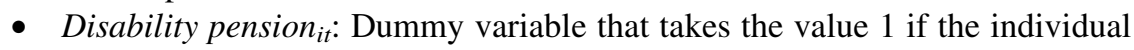
was perceiving a disability pension 1 year before each age.

- Contributory life characteristics:

- Unemployed ${ }_{i t}$ : Dummy variable that takes the value 1 if the individual was perceiving an unemployment benefit 1 year before each age.

- Number of SS relations : $_{i}$ Total number of contributory labour relations registered by the social security administration.

- Unique relation $:$ : Dummy variable that takes the value 1 if the individual had a unique relation throughout the worker's career.

- Number of years of contribution ${ }_{i t}$ : Total number of years of contribution to the social security system at each age/duration. The time spent perceiving unemployment benefits counts as contributive years towards an old-age 
pension as the INEM (Instituto de Empleo. Servicio Público de Empleo Estatal) is contributing.

- Sector of activity: Four categories for the sector of activity of the longest contract throughout the worker's career based on the contribution account code that follows the national classification of economic activities (CNAE93).

- Agriculture and Fisheries: 01, 02 and 05.

- Industry: 10-37, 40 and 41.

- Construction: 45.

- Services: 50-52, 55, 60-67, 70-75, 80, 85, 90-93, 95 and 99.

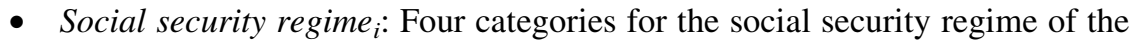
longest contract throughout the worker's career: general system, selfemployed, special agricultural system and others.

Descriptive statistics for the different incentives measures used in the analysis: see Tables 8, 9, 10, 11, 12, 13, 14.

Table 8 Estimated monthly retirement pension amounts at entry at each age (in 01/2007 euros)

\begin{tabular}{|c|c|c|c|c|c|c|}
\hline Age & Retirement route & Mean & Std. Dev. & $\mathrm{p} 10$ & $\mathrm{p} 50$ & $\mathrm{p} 90$ \\
\hline \multirow[t]{3}{*}{60} & Full & 772.53 & 317.54 & 461.31 & 673.41 & $1,266.69$ \\
\hline & Partial & $1,010.79$ & 461.46 & 458.83 & 930.35 & $1,711.25$ \\
\hline & Partial reduced & 671.81 & 256.00 & 442.08 & 571.36 & $1,076.69$ \\
\hline \multirow[t]{3}{*}{61} & Full & 869.66 & 373.58 & 472.34 & 775.86 & $1,444.18$ \\
\hline & Partial & $1,026.50$ & 459.03 & 477.24 & 947.41 & $1,735.25$ \\
\hline & Partial reduced & 750.41 & 306.18 & 447.85 & 658.49 & 1227.55 \\
\hline \multirow[t]{3}{*}{62} & Full & 979.16 & 424.41 & 506.40 & 888.11 & $1,631.88$ \\
\hline & Partial & $1,049.69$ & 456.52 & 501.78 & 971.56 & $1,762.58$ \\
\hline & Partial reduced & 839.45 & 352.71 & 457.17 & 753.91 & $1,387.10$ \\
\hline \multirow[t]{3}{*}{63} & Full & $1,092.16$ & 471.64 & 545.03 & 999.73 & $1,818.84$ \\
\hline & Partial & $1,072.98$ & 456.83 & 519.77 & 993.93 & $1,793.43$ \\
\hline & Partial reduced & 933.03 & 395.11 & 486.11 & 848.69 & $1,546.01$ \\
\hline \multirow[t]{3}{*}{64} & Full & $1,244.77$ & 528.73 & 606.27 & $1,151.46$ & $2,053.21$ \\
\hline & Partial & $1,094.82$ & 458.09 & 533.02 & $1,015.39$ & $1,826.59$ \\
\hline & Partial reduced & $1,027.93$ & 434.14 & 516.40 & 943.28 & $1,702.70$ \\
\hline \multirow[t]{2}{*}{65} & Full & $1,311.11$ & 541.75 & 646.13 & $1,218.96$ & $2,181.57$ \\
\hline & Partial & $1,114.78$ & 460.25 & 549.60 & $1,037.20$ & $1,854.33$ \\
\hline \multirow[t]{2}{*}{66} & Full & $1,332.19$ & 542.59 & 667.04 & $1,242.17$ & $2,207.49$ \\
\hline & Partial & $1,132.47$ & 460.99 & 567.54 & $1,056.59$ & $1,876.23$ \\
\hline
\end{tabular}

The reduced partial pension corresponds to a counterfactual policy design where partial pensions are subject to the application of reduction coefficients 
Table 9 Social security wealth (in 01/2007 euros)

\begin{tabular}{lllllll}
\hline Age & Retirement route & Mean & Std. Dev. & p10 & p50 & p90 \\
\hline 60 & Full & 205,422 & 84,082 & 123,771 & 179,336 & 334,840 \\
& Partial & 326,224 & 134,673 & 160,889 & 301,281 & 537,070 \\
61 & Full & 221,346 & 94,689 & 121,407 & 198,055 & 365,254 \\
& Partial & 318,235 & 130,774 & 148,430 & 294,905 & 523,816 \\
62 & Full & 238,724 & 103,105 & 123,285 & 216,460 & 395,152 \\
& Partial & 309,324 & 126,545 & 153,671 & 287,873 & 508,973 \\
63 & Full & 254,907 & 109,748 & 127,708 & 233,447 & 422,722 \\
& Partial & 300,217 & 122,487 & 149,423 & 279,988 & 494,778 \\
64 & Full & 278,238 & 118,266 & 134,032 & 257,632 & 457,519 \\
& Partial & 291,045 & 118,542 & 144,418 & 271,944 & 480,399 \\
65 & Full & 280,298 & 115,643 & 137,503 & 261,042 & 464,895 \\
& Partial & 281,777 & 114,673 & 140,099 & 263,612 & 465,723 \\
66 & Full & 272,549 & 110,921 & 135,906 & 254,855 & 450,931 \\
& Partial & 272,549 & 110,921 & 135,906 & 254,855 & 450,931 \\
\hline
\end{tabular}

Table 10 Social security accrual (in 01/2007 euros)

\begin{tabular}{rlrrrrr}
\hline Age & Retirement route & \multicolumn{1}{l}{ Mean } & Std. Dev. & p10 & p50 & p90 \\
\hline 60 & Full & 23,025 & 17,228 & 257 & 23,297 & 45,466 \\
& Partial & 1,790 & 3,898 & $-2,375$ & 1,579 & 6,219 \\
61 & Full & 24,847 & 15,982 & 3,315 & 25,134 & 44,810 \\
& Partial & 328 & 3,914 & $-4,123$ & 184 & 4,757 \\
62 & Full & 24,019 & 14,541 & 3,407 & 24,400 & 41,586 \\
& Partial & -390 & 3,039 & $-4,098$ & -326 & 3,140 \\
63 & Full & 31,313 & 20,966 & 3,359 & 28,190 & 61,825 \\
& Partial & $-1,312$ & 2,349 & $-4,349$ & $-1,080$ & 1,301 \\
64 & Full & 9,765 & 14,043 & $-7,300$ & 9,911 & 26,837 \\
& Partial & $-2,086$ & 1,743 & $-4,736$ & $-1,834$ & -256 \\
65 & Full & -479 & 9,872 & $-10,914$ & -555 & 11,066 \\
& Partial & $-2,616$ & 1,304 & $-4,617$ & $-2,429$ & $-1,145$ \\
\hline
\end{tabular}

Table 11 The implicit tax/subsidy imposed by the social security system

\begin{tabular}{lllllrr}
\hline Age & Retirement route & Mean & Std. Dev. & p10 & p50 & p90 \\
\hline 60 & Full & -1.1177 & 0.9135 & -1.9933 & -1.1406 & -0.0219 \\
& Partial & -0.1196 & 0.3082 & -0.3618 & -0.0929 & 0.1210 \\
61 & Full & -1.3298 & 1.0890 & -2.4488 & -1.1799 & -0.2708 \\
& Partial & -0.0448 & 0.3262 & -0.2942 & -0.0102 & 0.1873 \\
62 & Full & -1.3362 & 1.0742 & -2.6061 & -1.1345 & -0.3518 \\
& Partial & 0.0079 & 0.2442 & -0.1841 & 0.0188 & 0.1940 \\
\hline
\end{tabular}


Table 11 continued

\begin{tabular}{rlrlrrr}
\hline Age & Retirement route & \multicolumn{1}{l}{ Mean } & Std. Dev. & p10 & \multicolumn{1}{c}{ p50 } & p90 \\
\hline 63 & Full & -1.7910 & 1.6026 & -3.6140 & -1.3203 & -0.4218 \\
& Partial & 0.0689 & 0.1803 & -0.0735 & 0.0636 & 0.2124 \\
64 & Full & -0.5924 & 0.9298 & -1.4476 & -0.7088 & 0.3268 \\
& Partial & 0.1176 & 0.1247 & 0.0163 & 0.1054 & 0.2271 \\
65 & Full & 0.0140 & 0.8263 & -0.5866 & 0.0343 & 0.6527 \\
& Partial & 0.1495 & 0.0774 & 0.0845 & 0.1364 & 0.2354 \\
\hline
\end{tabular}

Table 12 The peak value (in 01/2007 euros)

\begin{tabular}{rlrrrrr}
\hline Age & Retirement route & \multicolumn{1}{c}{ Mean } & Std. Dev. & p10 & p50 & p90 \\
\hline 60 & Full & 123,890 & 63,633 & 27,311 & 128,279 & 203,954 \\
& Partial & 4,691 & 7,804 & $-2,020$ & 2,556 & 14,580 \\
61 & Full & 98,289 & 50,196 & 23,319 & 99,741 & 164,729 \\
& Partial & 1,680 & 6,001 & $-4,074$ & 484 & 9,030 \\
62 & Full & 71,639 & 36,882 & 19,423 & 70,948 & 121,259 \\
& Partial & 50 & 3,829 & $-4,085$ & -267 & 4,468 \\
63 & Full & 46,352 & 24,923 & 15,321 & 44,211 & 80,600 \\
& Partial & $-1,233$ & 2,513 & $-4,349$ & $-1,071$ & 1,452 \\
64 & Full & 13,106 & 15,661 & $-6,017$ & 12,476 & 32,361 \\
& Partial & $-2,082$ & 1,756 & $-4,736$ & $-1,834$ & -256 \\
65 & Full & -479 & 9,872 & $-10,914$ & -555 & 11,066 \\
& Partial & $-2,616$ & 1,304 & $-4,617$ & $-2,429$ & $-1,145$ \\
\hline \multirow{2}{*}{63} & & & & & &
\end{tabular}

Table 13 Delta social security wealth (in 01/2007 euros)

\begin{tabular}{lrrrrr}
\hline Age & Mean & Std. Dev. & p10 & p50 & p90 \\
\hline 60 & 122,592 & 62,063 & 30,296 & 125,282 & 202,173 \\
61 & 98,651 & 48,964 & 25,693 & 100,693 & 162,425 \\
62 & 72,214 & 36,754 & 21,245 & 72,503 & 121,331 \\
63 & 46,650 & 26,143 & 17,156 & 44,949 & 82,478 \\
64 & 14,069 & 17,440 & $-7,303$ & 14,034 & 35,376 \\
65 & 2,137 & 9,177 & $-7,403$ & 1,882 & 13,208 \\
\hline
\end{tabular}


Table 14 The relevant difference in delta social security wealth (in 01/2007 euros)

\begin{tabular}{llllll}
\hline Age & Mean & Std. Dev. & p10 & p50 & p90 \\
\hline 60 & $-26,496$ & 17,465 & $-48,906$ & $-27,909$ & 0 \\
61 & $-18,487$ & 11,212 & $-32,642$ & $-19,186$ & 0 \\
62 & $-11,358$ & 6,273 & $-19,224$ & $-11,634$ & -377 \\
63 & $-5,723$ & 2,979 & $-9,470$ & $-5,778$ & -333 \\
64 & $-1,842$ & 992 & $-3,109$ & $-1,851$ & 0 \\
\hline
\end{tabular}

The relevant difference in delta social security wealth is defined as the difference between the delta social security wealth in case partial retirement pensions are subject to reduction coefficients and the delta social security wealth under the current legislation

\section{References}

Arellano A, Zamarro G (2007) The choice between public and private schools with or without subsidies in Spain. Mimeo

Argimón I, Botella M, González C, Vegas R (2009) Retirement behaviour and retirement incentives in Spain. Banco de España Working Paper 0913

Blanco A (2000) The decision of early retirement in Spain. FEDEA, 2000, EEE 76

Blondal S, Scarpetta S (1998) Falling participation rates among older workers in OECD Countries: the role of social security systems. OECD Economic Department Working Paper

Boldrin M, Jiménez-Martín S, Peracchi F (1999) Social security and retirement in Spain. In: Gruber J, Wise D (eds) Social security programs and retirement around the World. Chicago University Press for the NBER, Chicago

Boldrin M, Jiménez-Martín S, Peracchi F (2004) Micro-modelling of retirement behavior in Spain. In: Gruber J, Wise D (Eds) Social security and retirement around the World: micro-estimation. Chicago University Press for the NBER, Chicago

Börsch-Supan A (2000) Incentive effects of social security on labor force participation: evidence in Germany and across Europe. J Public Econ 78:25-49

Bover O, Gómez R (2004) Another look at unemployment duration: exit to a permanent vs. a temporary job. Invest Econ 28(2):285-314

Brugiavini A, Peracchi (2003) Social security wealth and retirement decisions in Italy. Labour 17:79-114

Coile C, Grueber J (2000) Social security incentives for retirement. NBER Working Paper 7651

Dekkers G (2007) The financial implications of working longer: an application of a micro-economic model of retirement in Belgium. Int J Microsimul 1(1):10-25

Gruber J, Wise D (1999) Social security programs and retirement around the World. Chicago University Press for the NBER, Chicago

Gruber J, Wise D (2004) Social security programs and retirement around the World: micro-estimation. Chicago University Press for the NBER, Chicago

Instituto Nacional de Estadística (INE) (1968) Statistical 1968 Yearbooks. http://www.ine.es/ inebaseweb/hist.do

Instituto Nacional de Estadística (INE) (1999) Mortality tables of the Spanish population 1998-1999. General methodology. http://www.ine.es

Jenkins S (1995) Easy estimation methods for discrete-time duration models. Oxford Bull Econ Statist 57:129-138

Jiménez-Martín S, Sánchez-Martín A (2007) An evaluation on the life cycle effects of minimum pensions on retirement behavior. J Appl Econ 22:923-950

Jiménez-Martín S, Vall-Castelló J (2009) Business cycle effects on labour force transitions for older people in Spain. FEDEA Working Paper 2009-25

Ministerio de Trabajo y Asuntos Sociales, MTAS (2006) La muestra continua de vidas laborales. Colección Informes y Estudios. Serie Seguridad Social. Núm. 24

Narendranathan W, Stewart M (1993a) How does the benefit effect vary as unemployment spells lenghten. J Appl Econ 8:361-381

Narendranathan W, Stewart M (1993b) Modelling the probability of leaving unemployment: competing risk models with flexible base-line hazards. Appl Stat 42(1):63-83 
Stock J, Wise D (1990) Pensions, the option value of work and retirement. Econometrica 58(5):11511180

Sueyoshi G (1989) Social security and the determinants of full and partial retirement: a competing risks analysis. NBER Working Paper 3113

Sueyoshi G (1995) A class of binary response models for grouped duration data. J Appl Econ 10:411-431 